\title{
Optical, electro-optic and optoelectronic properties of natural and chemically modified DNAs
}

\author{
Young-Wan Kwon ${ }^{1}$, Dong Hoon Choi ${ }^{1,2}$ and Jung-Il Jin ${ }^{1}$ \\ This article reviews recent findings on the optical, electro-optic and optoelectronic properties of natural and modified DNAs. \\ When the sodium $\left(\mathrm{Na}^{+}\right)$ions of DNA are replaced with long alkyl quaternary ammonium $\left(Q^{+}\right)$ions, the resulting compositions \\ $\left(Q^{+}\right.$DNA $\left.^{-}\right)$are organic-soluble, and thin films produced using these materials reveal many interesting optical and \\ optoelectronic properties. These films tend to form well-structured supramolecular assemblies. In contrast, natural DNAs are \\ water-soluble and hygroscopic. DNAs are strong absorbers of UV wavelengths in the region of $260 \mathrm{~nm}$. The $\mathbf{Q}^{+} \mathrm{DNA}^{-}$films are \\ excellent dielectrics that can be utilized as insulating layers in organic thin film transistors. Chemical modification of the $\mathbf{Q}^{+}$ \\ parts results in many interesting structures that can be used in a wide variety of optical and optoelectronic devices. This review \\ specifically deals with the optical and fluorescence properties of, organic lasing composites, the nonlinear optical \\ characteristics of, light-emitting diodes, and photovoltaic cells based on natural and modified DNAs.
}

Polymer Journal (2012) 44, 1191-1208; doi:10.1038/pj.2012.165; published online 17 October 2012

Keywords: DNA; DNA ${ }^{-} \mathrm{Q}^{+}$; FRET; lasing; NLO; OLED; photovoltaic

\section{INTRODUCTION}

In recent years, the materials science of DNA has been attracting considerable interest, not only because some of the properties of DNA are very attractive for certain potential applications but also because one can make new discoveries by examining the behavior of these molecules, which can be translated into corresponding synthetic materials or mimics. Historically, the construction of many selfassembled architectures based on characteristic interchain or hydrogen-bonding interactions between the neighboring base pairs or the molecular and submolecular recognition capabilities of DNAs has been thoroughly studied by many research groups. Seeman ${ }^{1}$ pioneered this self-assembly approach. The construction of many interesting two- or three-dimensional architectures has been demonstrated via the self-assembly of modified DNAs. The molecular recognition properties of DNA are useful in the design of sensors and for diagnostic applications. The DNA-assisted preparation of metal nanoparticles and nanowires is considered to be potentially useful in the fabrication of nanoelectronics.

The science of DNA is the most important base for the recent progress in nanoscience and nanotechnology. The facile charge transport via DNA chains has been the subject of many important studies, especially pertaining to the concept of molecular wires. ${ }^{2}$ It is now clear that DNA double helices can be classified as wide bandgap semiconductors, ${ }^{3-6}$ although there are many variables ${ }^{7}$ to consider when one discusses the electrical properties of DNAs. Recently, our research group has been conducting a series of studies ${ }^{8-12}$ involving the measurement of the magnetic properties of natural DNA, surfactant-modified DNA and DNAs intercalated with paramagnetic dopants. We believe that the double-helical structure of DNA, when dehydrated, can promote ferromagnetic interactions with the dopants. Another important development in the materials science of DNA is the chemical transformation of water-soluble but organic-insoluble natural DNAs into organic-soluble compositions, which is achieved by simply replacing the sodium ions $\left(\mathrm{Na}^{+}\right)$of the original structure with long alkyl chain quaternary ammonium $\left(\mathrm{Q}^{+}\right)$groups. ${ }^{13}$ This transformation imparts various functionalities to the resulting materials. This chemistry is rapidly expanding the horizons of the materials science of DNA. The long alkyl groups tend to induce the formation of self-assembled three-dimensional architectures ${ }^{14,15}$ through the hydrophobic interactions between them.

The aims of this article are to review the results of our own and other groups' research on the photonic properties of DNA, both natural and modified, and to discuss the future perspectives of this research. We previously published a review article ${ }^{16}$ on the broader spectrum of the materials science of DNA. Recently, Su et al. ${ }^{17}$ discussed DNA-programmed photonic arrays and devices. They also suggested future opportunities in the area of DNA photonics. Steckl et al. ${ }^{18}$ wrote an interesting article entitled 'DNA as an optical material.'

\section{OPTICAL PROPERTIES OF DNA}

Figures 1 and 2 compare the UV-Vis absorption spectra of natural salmon sperm $\mathrm{DNA}^{16}$ and $\mathrm{DNA}^{-} \mathrm{Q}^{+}$complexes $^{19}$ in solution and in solid films. 
The first strong absorption band of natural DNA (Figure 1) below $225 \mathrm{~nm}$ originates from the overlapping electronic absorptions of sugar moieties and phosphate groups. The second absorption, whose maximum is located at $\sim 260 \mathrm{~nm}$, is the result of electronic transitions of the four heterocyclic bases in the nucleic acids. The absorption edge of this peak is $\sim 300 \mathrm{~nm}$. Figure 1 shows that the UV-Vis absorption positions of the solid films are only slightly shifted in the red direction, and the sharpness of the peak is also largely unchanged compared with those of the solutions. This observation suggests that agglomeration among the double helices of DNA does not significantly occur in the solid and that the layer-to-layer hybridization perpendicular to the long axis of the double helix is inefficient. There have been many controversies ${ }^{20}$ concerning the conduction or charge-transport properties of DNA. The semiconducting molecular wire concept of DNA is persistent but also controversial, although the conformational dynamics of the flexible helical structure may be the key factors that control the migration of carriers. The term 'conformational gating ${ }^{21,22}$ was coined by Barton's group to describe this phenomenon.

Figure 2 compares the electronic spectra of three different DNA ${ }^{-}$ $\mathrm{Q}^{+}$compositions ${ }^{19}$ with that of natural DNA or $\mathrm{DNA}^{-} \mathrm{Na}^{+}$, both in solution and in solid form. Although the details of their absorption spectra are not the same, their absorption positions are more or less similar. This result can be taken as an implication that replacing the $\mathrm{Na}^{+}$counter-ions with $\mathrm{Q}^{+}$ions does not cause fundamental changes in the electronic structure of the original DNA backbone. Furthermore, the spectra of the $\mathrm{DNA}^{-} \mathrm{Q}^{+}$compositions in solution were also not considerably different from those in the solid state. This observation is rather surprising because the conformation or the three-dimensional structure of DNA strongly depends on its water content; wet DNA in the so-called B-form is transformed by dehydration into the A-form. It is known that in the wet B-form, a single helical turn contains 10 base pairs, where the average distance between neighboring base planes is $3.4 \AA$ and the diameter of the helix is $20 \AA$. In contrast, the $\mathrm{A}$-form makes a single turn with 11 base pairs and the interbasal plane distance is significantly shorter $(2.55 \AA)$ than in the B-form. At the same time, dehydration expands the helical structure such that it has a diameter of $26 \AA$. The fact that the UVabsorption spectra of the A- and B-forms are practically the same strongly suggests that the electronic excitations primarily originate from the electrons in the basal planes rather than those involved in $\pi_{\mathrm{z}}$-delocalization in the perpendicular direction. ${ }^{23}$

The circular dichroic (CD) spectra of $\mathrm{Na}^{+} \mathrm{DNA}^{-}$and $\mathrm{Q}^{+} \mathrm{DNA}^{-}$ complexes in solution and in a dry film were studied by Tanaka and Okahata. ${ }^{13}$ The authors demonstrated that the replacement of $\mathrm{Na}^{+}$ ions with $\mathrm{Q}^{+}$ions did not change the conformation of the DNA backbone, and consequently, the basic features of the CD spectra did not change (Figure 3). However, the CD spectra of the films strongly depended on the content of water or solvent.

The authors concluded that the B-form is transformed into the A-form via the intermediate $\mathrm{C}$-form as the water content is reduced. Note that the CD behavior of the present DNA samples is not the result of electronic interactions in the base pairs but is induced by the asymmetric helicity of the overall DNA molecular structures.

Grote et al. ${ }^{24}$ studied the optical properties of DNA-CTMA (cetyltrimethyl ammonium) complex films in detail. These films exhibit excellent light transmission over a very broad wavelength range, as shown in Figure 4. Furthermore, the refractive index ${ }^{25}$ of these films remained constant, at slightly $>1.526$, over the wavelength range of 1000-1250 nm (Figure 5). These observations imply that DNA-CTMA films may find applications as optical waveguide

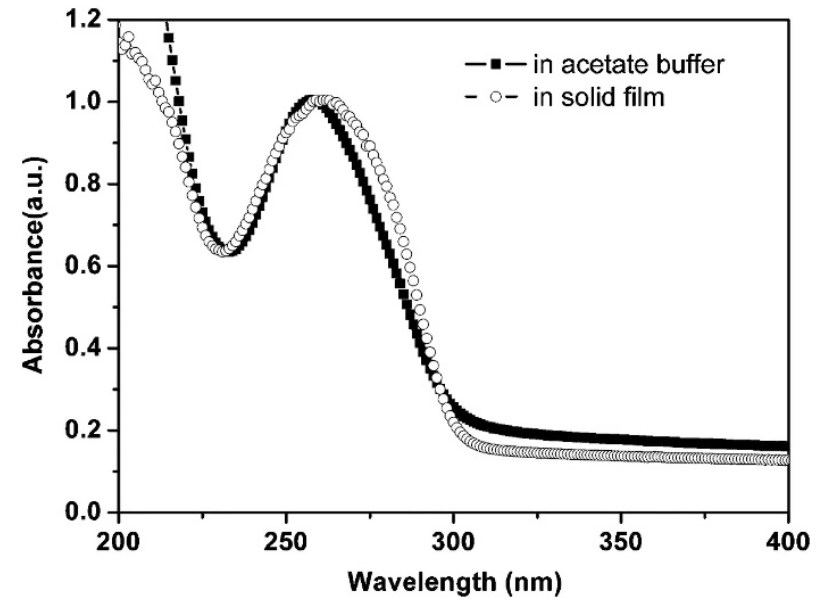

Figure 1 UV-Vis absorption spectra of DNA in an acetate buffer and in a thin solid film ${ }^{16}$ (reprinted with permission from Kwon et al., ${ }^{16}$ copyright (2009) Royal Society of Chemistry).
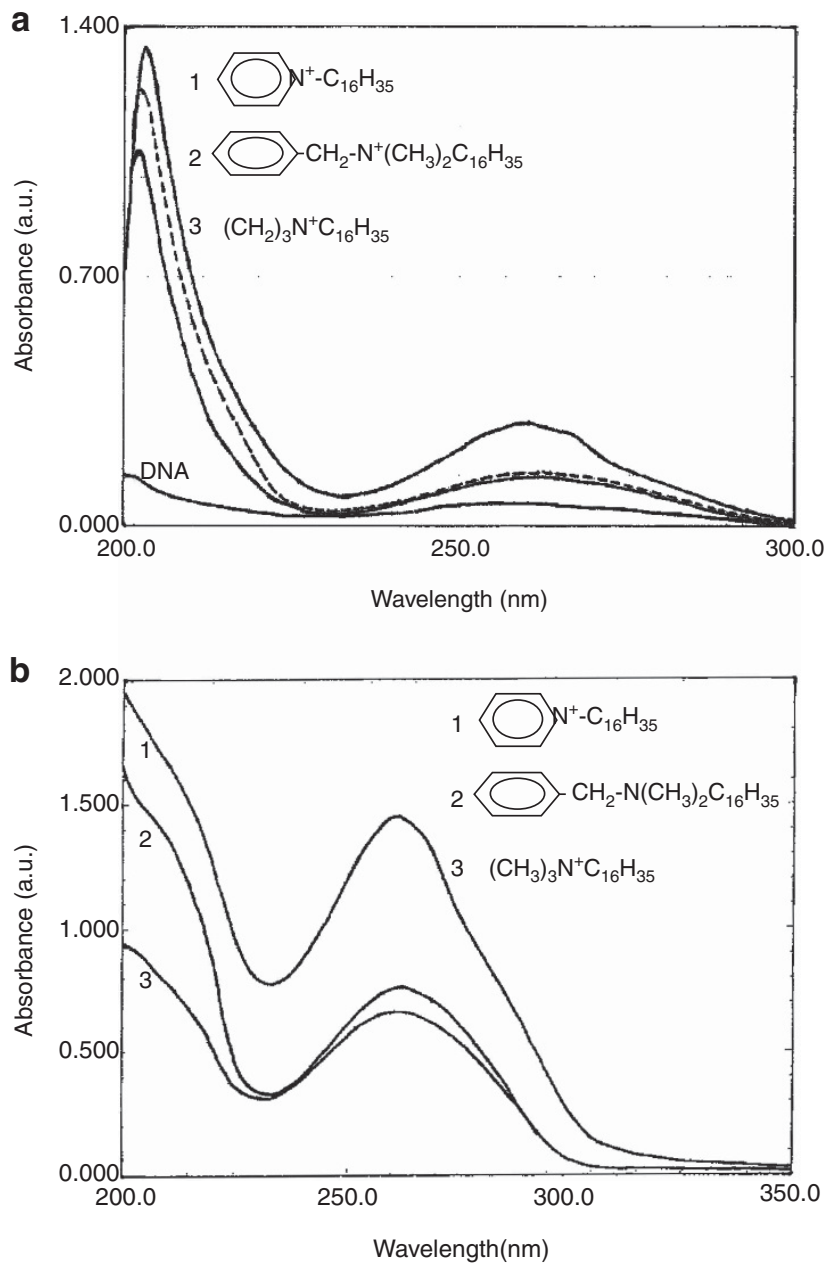

Figure 2 UV-Vis absorption spectra of (a) $25 \mathrm{~mm}$ DNA and DNA surfactant (CTMA, BDMA, and CP) complexes in ethanol solution and (b) in films

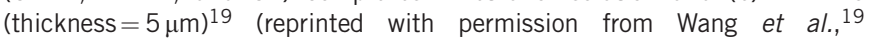
copyright (2001) American Chemical Society). 


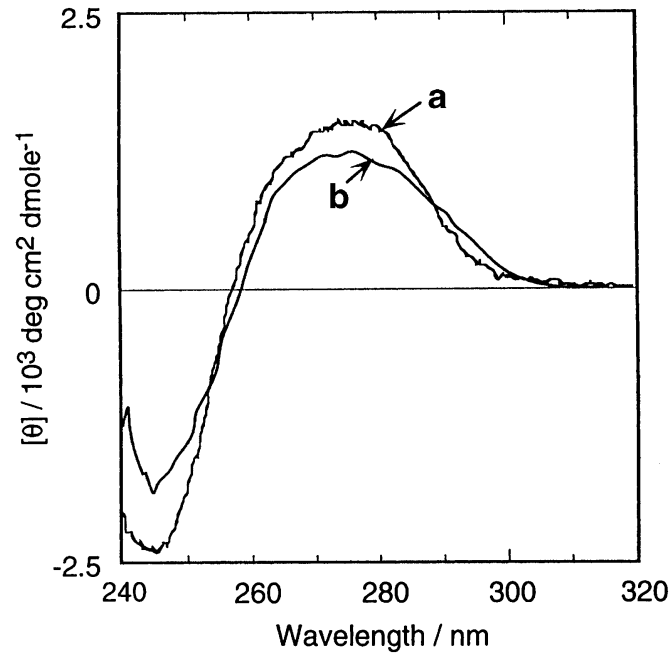

Figure $3 \mathrm{CD}$ spectra of (a) DNA-lipid complex in $\mathrm{CHCl}_{3} / \mathrm{EtOH}$ / $\mathrm{H}_{2} \mathrm{O}=4: 1: 0.07$ and (b) native DNA in an aqueous buffer solution $(20 \mathrm{~mm}$ $\mathrm{NaCl}, \mathrm{pH} 7.8,10 \mathrm{~mm}$ Tris, $\left.[\mathrm{DNA}]=50 \mathrm{mmbp}^{-1}, 23^{\circ} \mathrm{C}\right)^{13}$ (reprinted with permission from Tanaka and Okahata, ${ }^{13}$ copyright (1996) American Chemical Society).

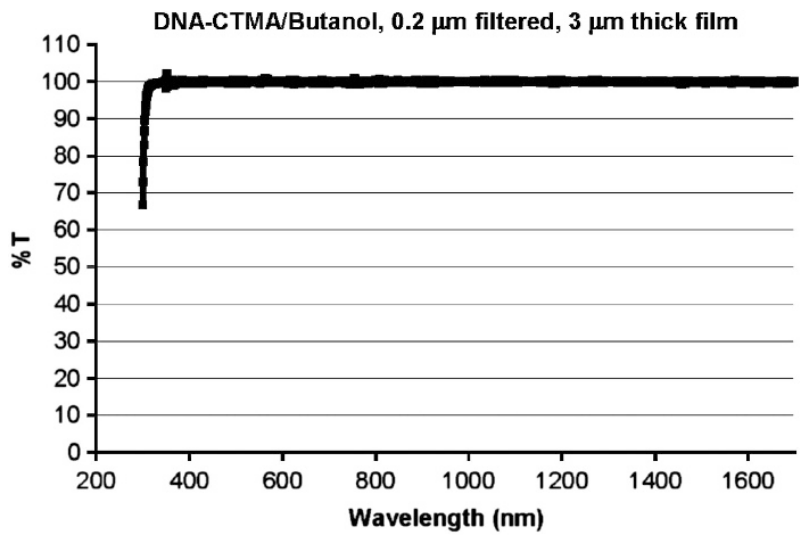

Figure 4 Transmissivity of a 3-um thick DNA-CTMA thin film. (reprinted with permission from Grote et al.,24 copyright (2004) American Chemical Society).

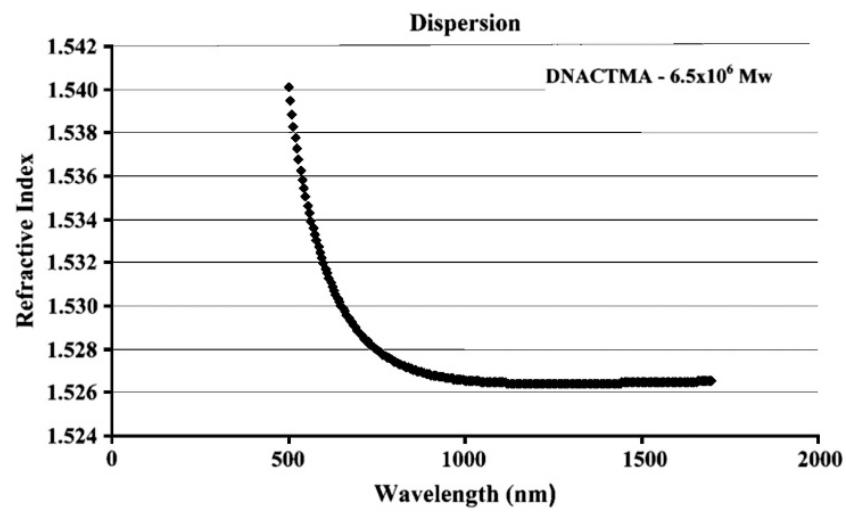

Figure 5 Refractive index of DNA-CTMA ${ }^{25}$ (reproduced with permission from Grote et al., ${ }^{25}$ copyright (2005) Taylor \& Francis). materials and also as optical cladding for nonlinear electro-optic modulators.

\section{FLUORESCENCE OF DYE-DOPED DNAS}

The fluorescence or photoluminescence (PL) behavior of many dyes has been the subject of many research papers and books. ${ }^{26,27}$ Earlier, Ohnishi ${ }^{28}$ thoroughly discussed the stability of double-stranded DNA on the basis of polyelectrolyte theory. Record et al. ${ }^{29}$ also provided a thorough review on the conformations and interactions with the ligands of double-helical DNA. In connection with the subject of this section, understanding the binding ability of polyelectrolytes for dye molecules can be of great importance. ${ }^{30,31}$

Very often, we observe that the fluorescence efficiency or quantum yield diminishes when we increase the concentration of dye in solution. This effect is called concentration quenching. The same phenomenon limits how much fluorescent dye one can mix into a solid substrate, such as poly(methyl methacrylate), PMMA, without losing the PL efficiency. Preventing the formation of dye aggregates is the most important factor for minimizing the concentration quenching effect. One way to prevent aggregate formation is to find a method where the dye molecules are kept at a distance from each other in a matrix such that there are no electronic interactions between them. The intercalation ${ }^{26}$ of fluorescent molecules into a DNA substrate has been attempted to compartmentalize the dye molecules. In the 1960s and 1970s, strong fluorescence enhancement in a solution of ethidium bromide was observed when DNA was added into the solution, which was the topic of intensive studies. Among the many different mechanisms proposed to explain this enhancement, the intercalation of ethidium bromide into DNA is the most plausible one. ${ }^{27,32}$

More recently, the fluorescence spectra of 4-[4-(dimethylamino)styryl]-1-dodecyl pyridinium bromide (DMASDPB) mixed with DNA-CTMA were studied by Grote et al. ${ }^{24}$

As shown in Figure 6, the film containing the lowest level of dye presented the greatest fluorescence intensity. Compartmentalization of the dye molecules in the DNA-CTMA matrix must be the reason for this observation. The physical picture of the mixtures, however, is
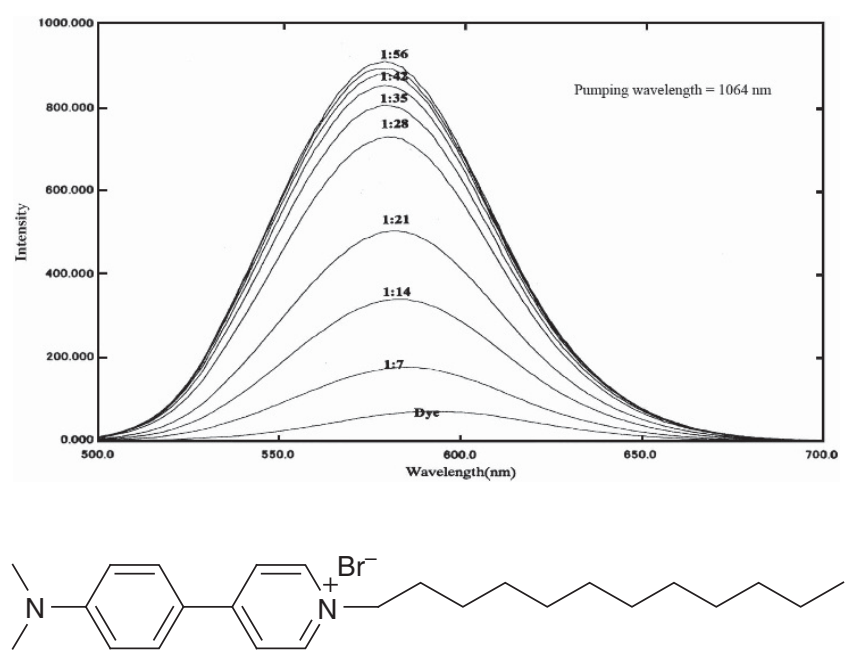

Figure 6 Fluorescence versus wavelength for various ratios of DMASDPB in DNA-CTMA ${ }^{24}$ (reprinted with permission from Grote et al., ${ }^{24}$ copyright (2004) American Chemical Society). 
much more complicated; the location of the dye molecules in the substrate is not well defined, and during the preparation of the mixtures in ethanol solution, exchange reactions between the dye and CTMA are possible because they are both quaternary ammonium compounds. However, the extent of this reaction was not characterized. A portion of the dye molecules could also enter the region between the basal planes and intercalate into the core region of the DNA double helix, and some molecules could intercalate into the CTMA part. The two portions of the dye molecules are in different surroundings, which results in dissimilar fluorescence behaviors of the dye molecules.

We doped DNA-CTMA with a nonionic dye, (E)-2-[2-(4-diethylaminostyryl)-4H-pyran-4-ylidene] malonitrile (DCM), ${ }^{33}$ in a chloroform/alcohol mixture (9:1 by volume). The resulting thin films were subjected to PL measurements. For comparison, DCM was mixed with PMMA in chloroform.

As shown in Figure 7, the PL intensity of the DCM-doped DNA increases up to the dopant concentration of $10 \mathrm{wt} \%$, whereas in PMMA, the PL intensity starts to diminish at only $3 \mathrm{wt} \%$ of dopant. This result indicates that DNA accommodates the DCM molecules more efficiently than PMMA. The dopant molecules can intercalate into different parts of the DNA, which results in a better dispersion of the dye molecules in the matrix. The amount of the dopant in the different locations remains to be quantified.

We previously prepared a series of organic-soluble DNAs containing varying ratios of two different fluorophores in the $\mathrm{Q}^{+} \mathrm{DNA}^{-}$, as depicted in the following synthetic scheme ${ }^{34}$ (Figure 8).

The carbazole $(\mathrm{Cz})$ and pyrenylvinylenephenylene (PVP) moieties were randomly positioned along the surrounding lipid portion of the double-stranded DNA. Figure 9 shows that an inclusion of only $2.2 \mathrm{wt} \%$ of the PVP structure completely quenches the PL emissions of the $\mathrm{Cz}$ moieties at 356 and $372 \mathrm{~nm}$ and that only emissions by the PVP moieties at 436 and $457 \mathrm{~nm}$ are observed. This result indicates the presence of an extremely efficient energy transfer from the excited state of the $\mathrm{Cz}$ unit (donor) to the PVP units (acceptor) via the socalled fluorescence resonance energy transfer (FRET) or Förster energy transfer mechanism. ${ }^{35}$ The proximity of the donor-acceptor fluorophore pairs must promote efficient electronic interactions between them to result in a facile FRET. The special organization of the donor and acceptor moieties must be a key factor. Further structural or morphological studies are required to analyze the experimental observations in a more quantitative manner. Excellent studies on the FRET of synthetic DNAs bearing a donor-acceptor structure have been reported by others. ${ }^{35}$

Figure 9 also reveals that increasing the concentration of PVP rapidly decreases the PL intensity, which is accompanied by significantly enhanced absorption at $\sim 390 \mathrm{~nm}$, which is believed to be due to the formation of PVP aggregates. We believe that this formation of aggregates is also the cause of the decreased PL intensity at 436 and $457 \mathrm{~nm}$ with increasing PVP units in the copolymeric $\mathrm{Q}^{+} \mathrm{DNA}^{-}$compositions. When the copolymeric DNA containing $11.4 \mathrm{wt} \%$ of the PVP structure was mixed with DCM in varying proportions, the PL of the mixtures provides an excellent example of cascade energy transfer from the $\mathrm{Cz}$ moieties to the DCM molecules through the PVP units (see Figure 10). Figure 10a is the PL spectrum of the substrate polymer. When this polymer was mixed with $0.3 \mathrm{wt} \%$ of DCM, two PL peaks appeared at $\sim 460$ and $565 \mathrm{~nm}$; the former results from the PVP unit, and the latter results from the DCM dopant.

When the DCM content was increased to $5 \mathrm{wt} \%$, the redshifted PL spectrum (Figure 10) originating from the DCM dopant appeared
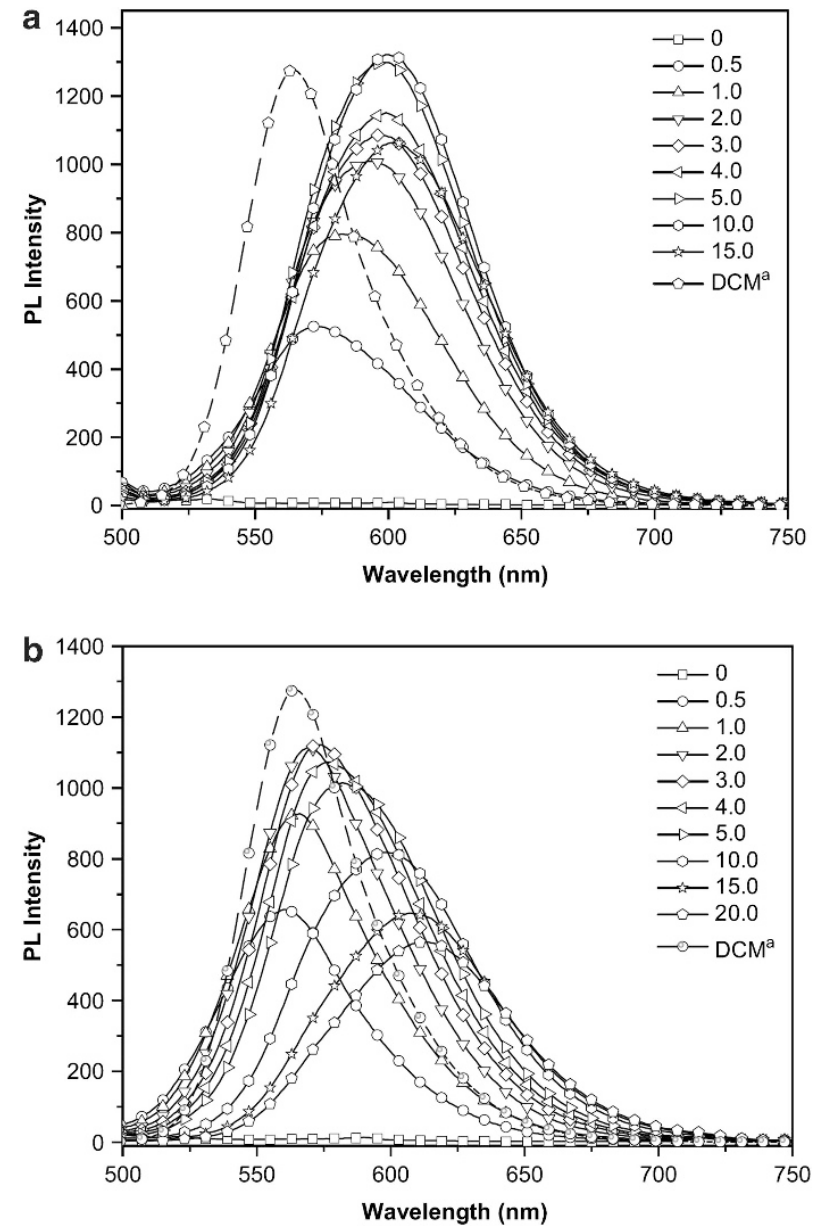

Figure 7 Photoluminescence spectra of DNA-CTMA and PMMA doped with the DCM dye. Effect of dye concentration on the photoluminescence spectral behaviors. ${ }^{33}{ }^{*}$ Sample: thin film with an identical thickness. ( $t$ is $\sim 100 \mathrm{~nm}$ ) (a) CTMA-DNA. (b) PMMA. a Solution in chloroform (reprinted with permission from Lee et al., ${ }^{33}$ copyright (2008) Elsevier).

at $\sim 600 \mathrm{~nm}$. The emission from the PVP structure was almost completely suppressed. A cascade energy transfer from the $\mathrm{Cz}$ units to the DCM dopants via the PVP moieties was achieved and resulted in the display of red emission.

The concept of DNA-programmed photonic wire, which was first reported in 1999 by a Japanese group, ${ }^{36}$ has since been expanded by many research groups. A recent article on DNA-templated photonic arrays and assemblies by $\mathrm{Su}$ et al. ${ }^{37}$ provides an excellent analysis of the different approaches and outlooks for this concept. The intercalation of energy relay dye molecules into DNA and the use of DNA minor groove binders are two important methods for assembling the photonic arrays on dsDNA templates.

$\mathrm{Yu}$ et al. ${ }^{38}$ prepared a series of solid films composed of the fluorescing polymer $186 \mathrm{Q}$ and natural DNA in different ratios and examined their PL behavior.

As shown in Figure 11, when the polymer dye was diluted 750 times with DNA, the PL intensity was the strongest. Simultaneously, this mixture exhibited the slowest decay in fluorescence, as depicted in Figure 12. Because the polymer $186 \mathrm{Q}$ possesses quaternary 

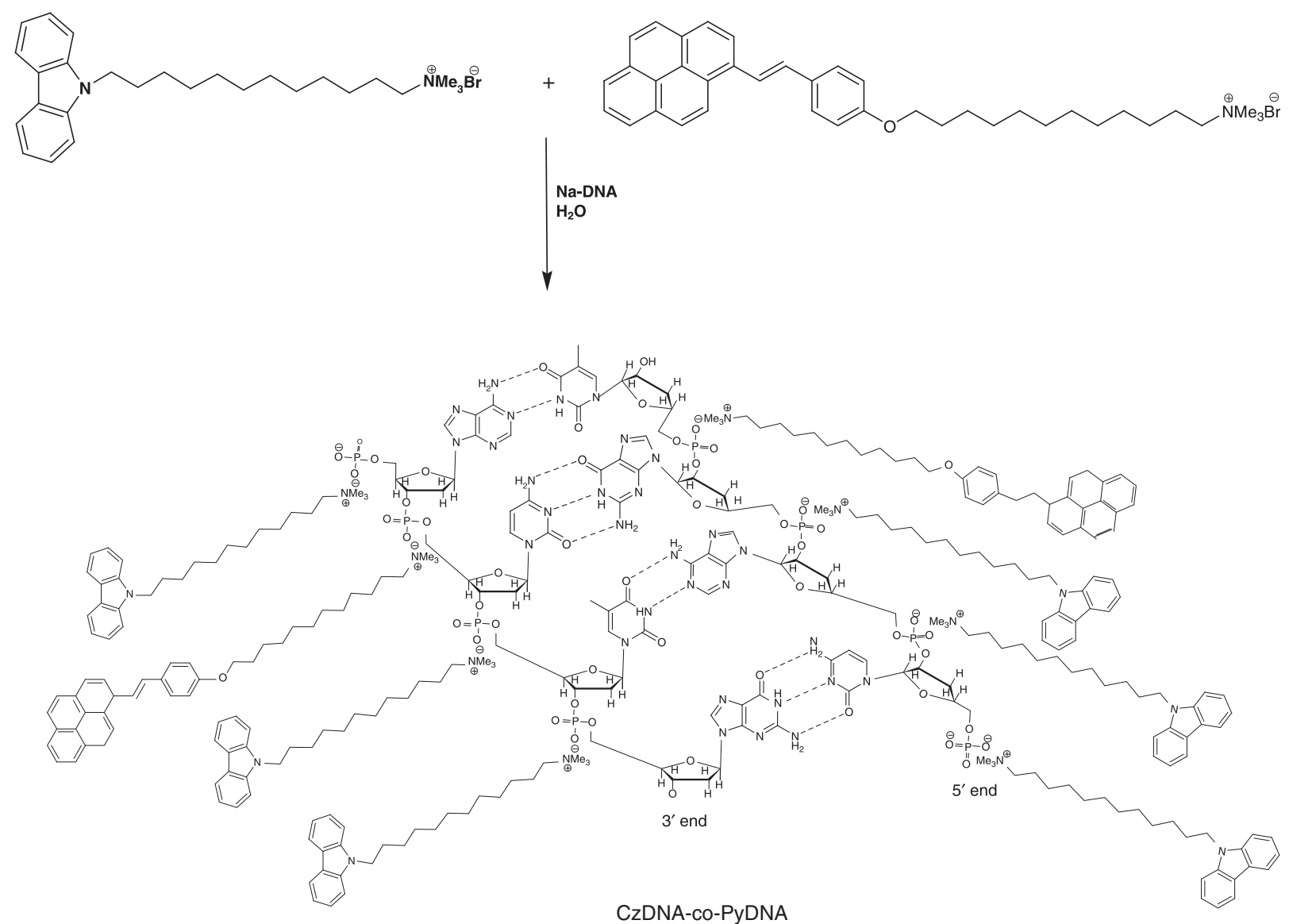

Figure 8 Synthetic procedure for CzDNA-co-PyDNA; copolymers with 2.2, 4.2, 7.1, and 11.4 wt\% of pyrene moiety ${ }^{34}$ (reprinted with permission from Lee et al., 34 copyright (2009) Wiley-VCH Verlag GmbH \& Co., KGaA, Weinheim).
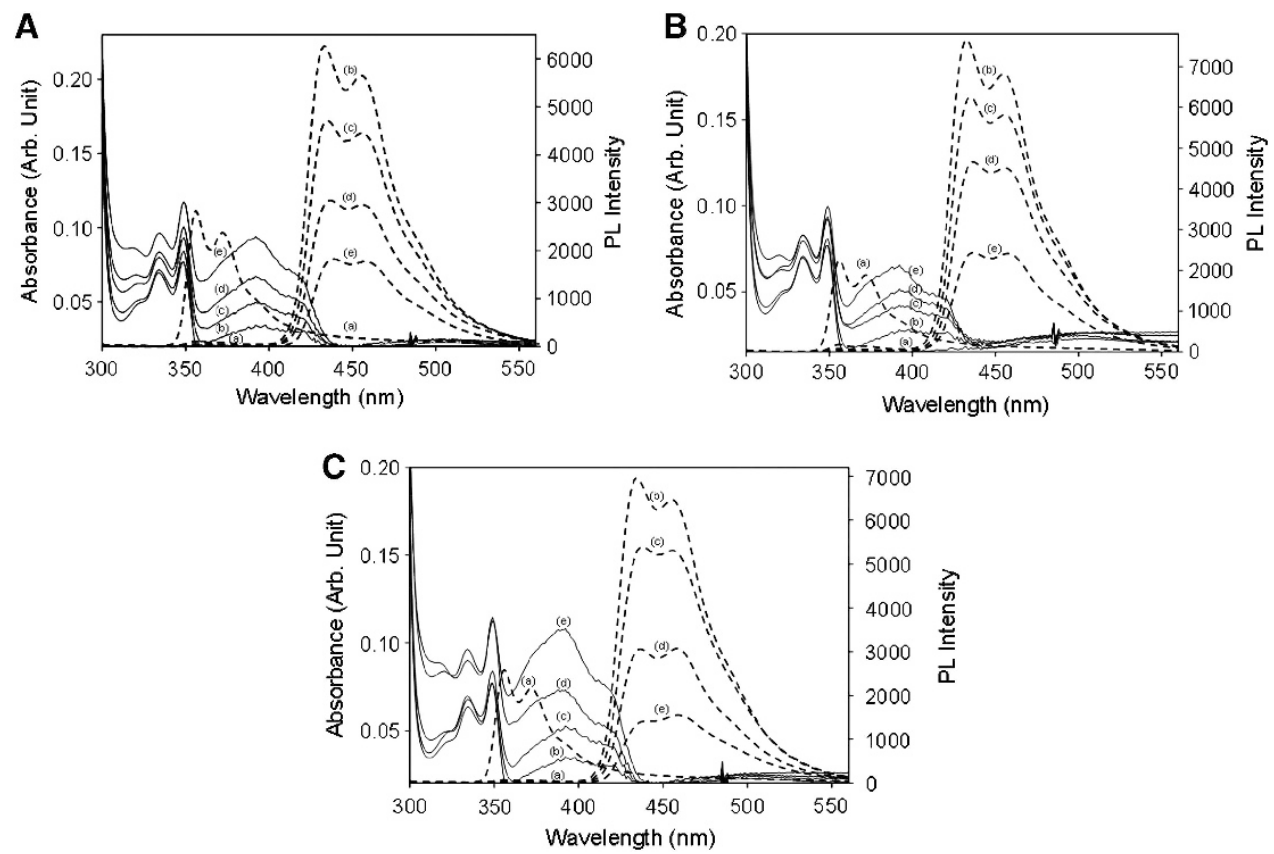

Figure 9 Absorption and PL spectra of three polymeric samples in solution with varying pyrene moiety concentrations. A: guest-host systems, where the guest is (E)-1-(4-(12-bromododecyloxy)styryl)pyrene and the host is CzDNA; B: blends of CzDNA and PyDNA, C: CzDNA-co-PyDNA copolymers. ${ }^{34}$ ${ }^{*}$ Concentrations of pyrene moiety: (a) $0 \mathrm{wt} \%$, (b) $2.2 \mathrm{wt} \%$, (c) $4.2 \mathrm{wt} \%$, (d) $7.1 \mathrm{wt} \%$, and (e) $11.4 \mathrm{wt} \%$. * Solid lines: absorption spectra; Dashed lines: PL spectra (reprinted with permission from Lee et al., ${ }^{34}$ copyright (2009) Wiley-VCH Verlag GmbH \& Co., KGaA). 
ammonium $\left(\mathrm{Q}^{+}\right)$side chain structures, ion exchange reactions between the $\mathrm{Na}^{+}$ions of DNA and the $\mathrm{Q}^{+}$ions of 186Q must have occurred. These ion exchange reactions must have resulted in the formation of polyelectrolyte complexes between the 186Q and DNA chains, which can effectively disperse the $186 \mathrm{Q}$ chains in the DNA matrix. This dilution of $186 \mathrm{Q}$ is expected to hinder the formation of aggregates among the fluorescing polymer chains, which consequently increases the PL efficiency and PL lifetime.

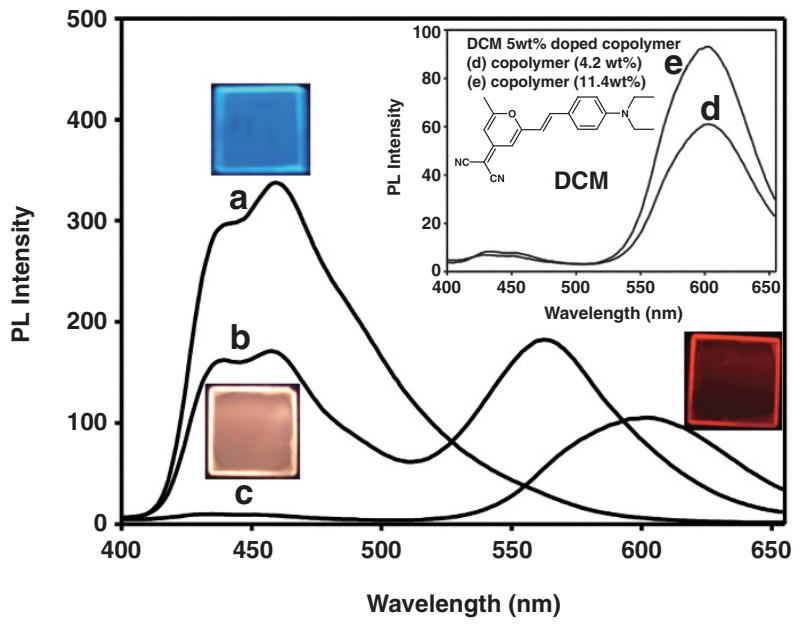

Figure $10 \mathrm{PL}$ spectra of the copolymer film bearing $11.4 \mathrm{wt} \%$ pyrene moieties and its mixtures with DCM dye; (a) 11.4 wt\%, (b) 11.4 wt\% doped with 0.3 wt\% DCM, and (c) 11.4 wt\% doped with 5.0 wt\% DCM *Inset: (d) 4.2 wt\% doped with 5.0 wt\% DCM and (e) 11.4 wt\% doped with 5.0 wt\% DCM. *Sample: film (thickness $\sim 60 \mathrm{~nm}$ ) ${ }^{34}$ (reprinted with permission from Lee et al., ${ }^{34}$ copyright (2009) Wiley-VCH Verlag GmbH \& Co., KGaA).
Vauthey and coworkers ${ }^{39}$ conducted a study on the ultrafast excited-state dynamics of fluorescent intercalants of DNA and clarified the mechanism for the enhanced fluorescence by the intercalators.

\section{DNA-BASED LASING}

The Chitose group led by Ogata in Japan ${ }^{40}$ presented an interesting report where one-photon excited amplified spontaneous emission

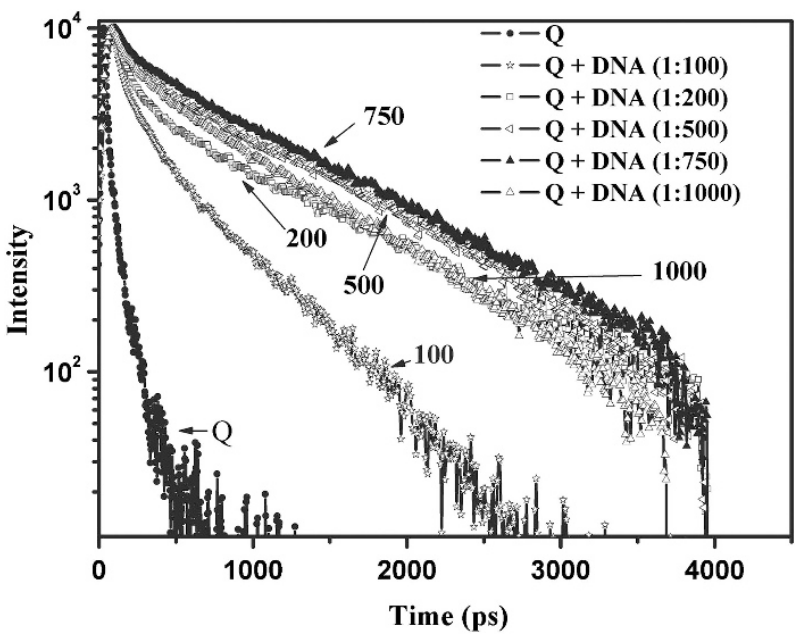

Figure 12 Time-resolved fluorescence decay profiles of DNA/Polymer $Q$ blend films $\left(\sim 1.0 \mu \mathrm{m}\right.$ thick) $\left(\lambda_{\mathrm{em}}=510 \mathrm{~nm}\right)^{38}$ (reprinted with permission from Yu et al., 38 copyright (2009) The Polymer Society of Korea).
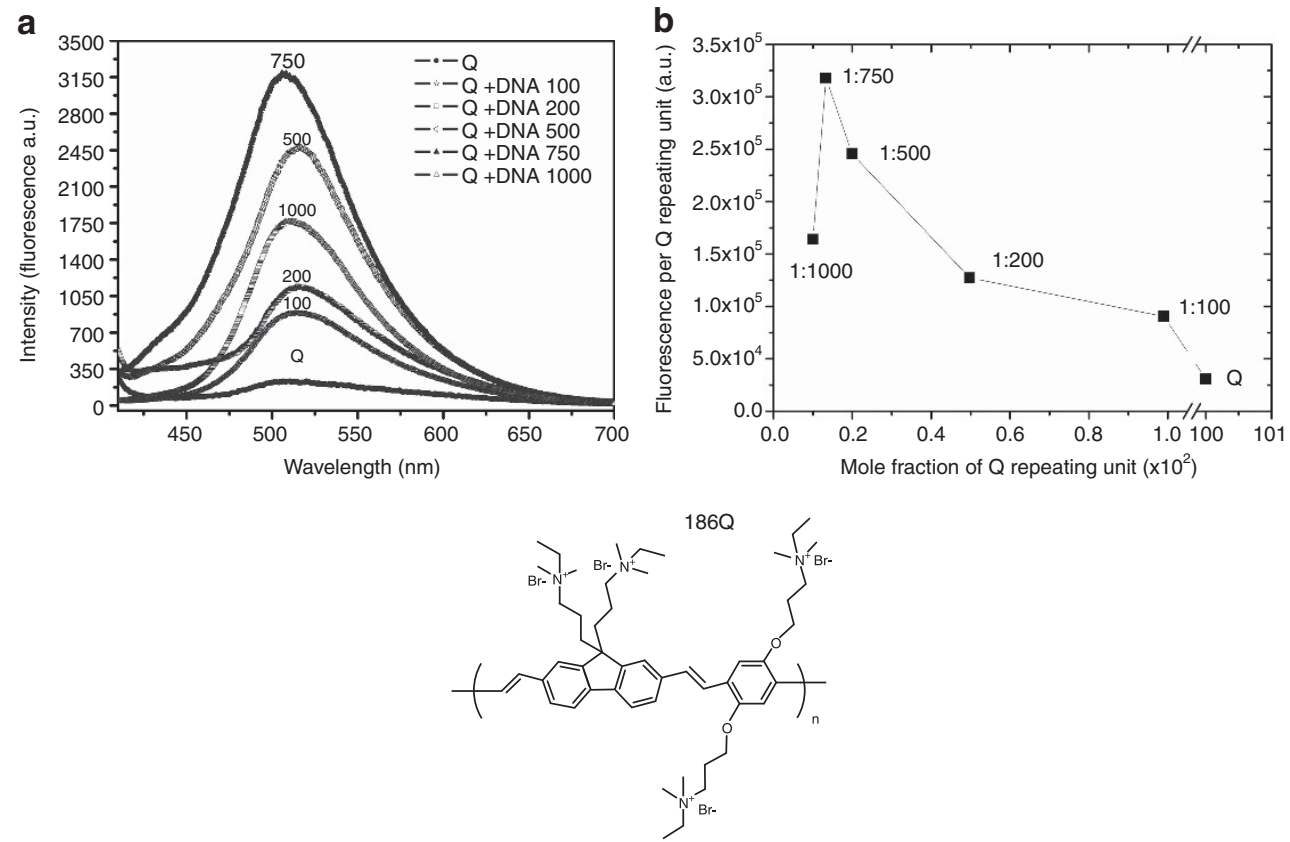

Figure 11 Fluorescence spectra (a) of DNA-Q complexes (molar ratio of the repeating unit) and (b) dependence of fluorescence intensity per the $Q$ repeating unit on the mole fraction of $Q$ units in the mixture ${ }^{38}$ (reprinted with permission from Yu et al., ${ }^{38}$ copyright (2009) The Polymer Society of Korea). 

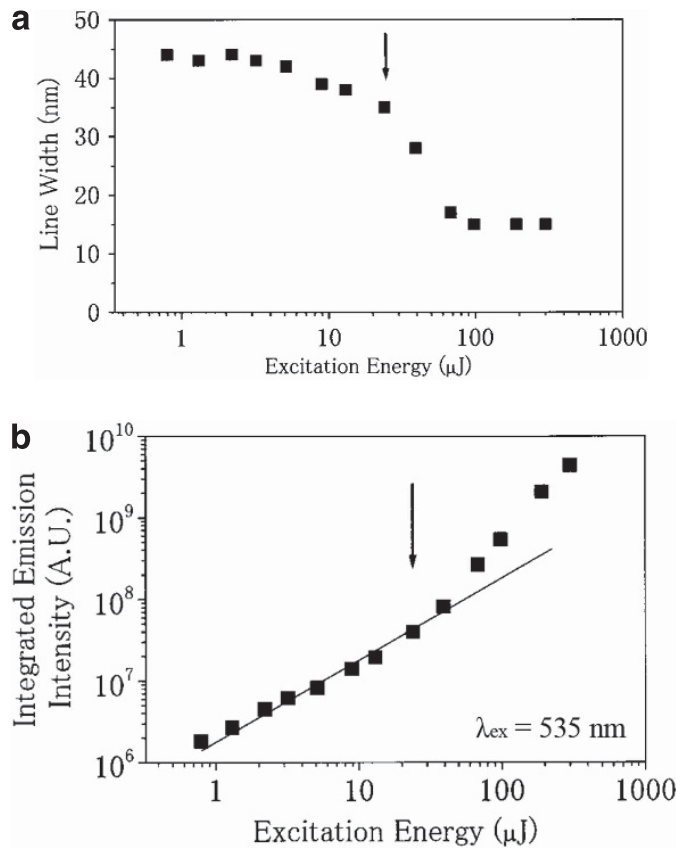<smiles></smiles>

Figure 13 (a) Linewidth of emission spectra as a function of excitation energy. The arrow indicates the threshold energy where line narrowing occurs. (b) Relative energy of emitted light as a function of excitation energy. The arrow indicates the threshold energy. The solid line shows a slope $=1^{40}$ (reprinted with permission from Kawabe et al., ${ }^{40}$ copyright (2000) Wiley-VCH Verlag GmbH \& Co., KGaA).

(ASE) was observed when the DNA-CTMA complex was doped with Rhodamine $6 \mathrm{G}$ at $1.36 \mathrm{wt} \%$. The film was pumped by a nanosecond $532 \mathrm{~nm}$ laser beam.

Figures 13a and $\mathrm{b}$, respectively, show the change in linewidth of the emission peak as a function of the excitation energy and the dependence of the relative energy of the emitted light on the excitation energy. Both the line narrowing and superlinear dependence of the emitted light intensity occur at $\sim 20 \mu \mathrm{J}$, which is strong evidence for the occurrence of light amplification. This report triggered many studies that examined the possible lasing capacities of different DNA-based composites. Grote et al. ${ }^{24}$ reported that films composed of a DNA-CTMA/europium complex revealed a strong amplification of fluorescence at $614 \mathrm{~nm}$ when irradiated with UV light. More recently, He et al. ${ }^{41}$ reported cavity-enhanced two-photon excited frequency up-conversion lasing in a DNA-CTMA 4-[4-(bis(2chloroethyl)amino)styryl]-1-methyl pyridinium tosylate gel using ultrashort IR pulses $(775 \mathrm{~nm})$. The dye they utilized is known to be a highly multiphoton-active lasing dye.

Figure 14 compares the emission spectra of two-photon induced fluorescence, cavityless lasing, and cavity-enhanced lasing. The FWHM of these spectra are 61, 17, and $12 \mathrm{~nm}$, respectively.
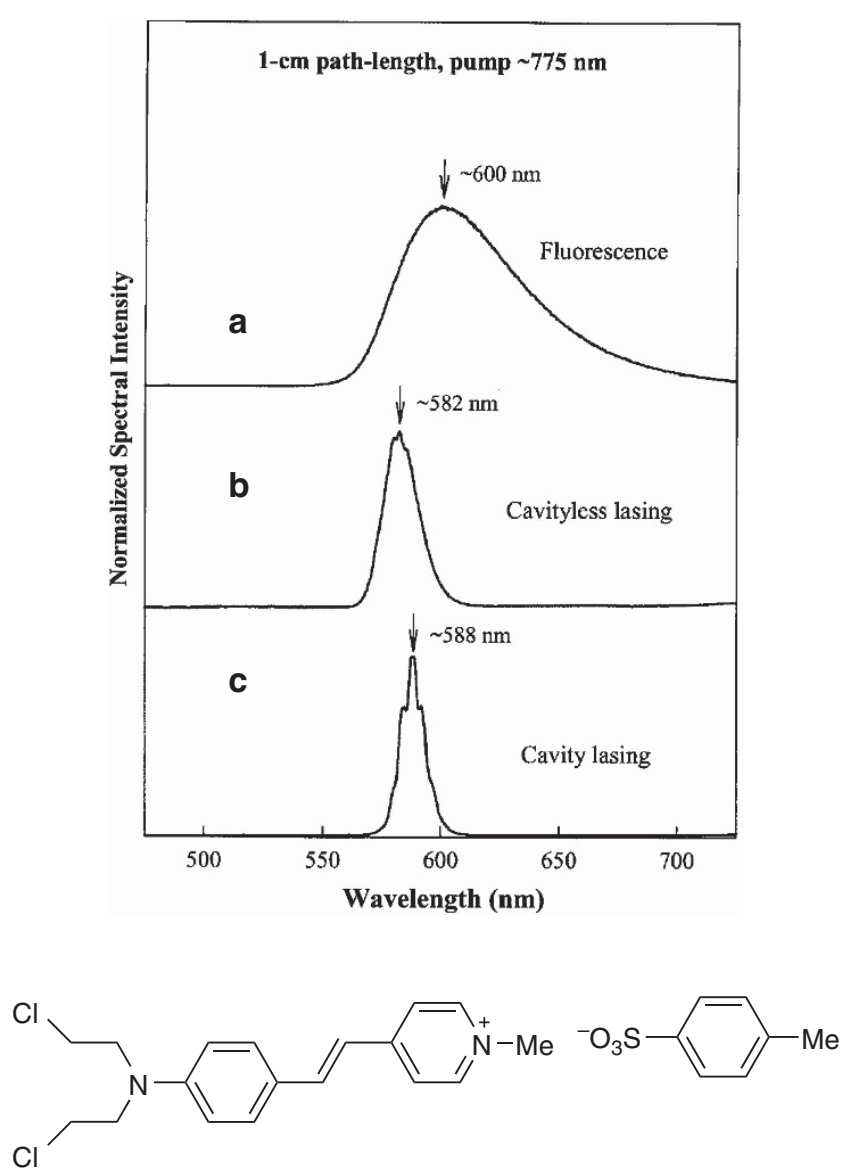

Figure 14 Measured spectral curves for (a) two-photon induced fluorescence, (b) forward cavityless lasing, and (c) forward cavity-enhanced lasing $^{41}$ (reprinted with permission from He et al., ${ }^{41}$ copyright (2006) Optical Society of America).

The advantages of using ultrashort IR laser pulse pumping include increased penetration depth into biological media and lower pulse energy. In relation to the above report, Yu et al. ${ }^{42}$ fabricated distributed feedback (DFB) lasing structures that consist of a grating etched into an $\mathrm{SiO}_{2}$-Si wafer substrate where a DNACTMA/sulforhodamine 640 (SRh) dye layer was deposited. The anionic SRh dye, whose lasing wavelength ranges from 610 to $670 \mathrm{~nm}$ depending on usage conditions, is a red-emitting fluorophore that is frequently utilized in dye lasers.

The results from the authors are summarized in Figures 15 and 16a and $b$. Figure 15 compares the spectra obtained under ASE and DFB lasing conditions. The DFB emission peak width at $650 \mathrm{~nm}$ is $<1 \mathrm{~nm}$ compared with $10 \mathrm{~nm}$ for the corresponding ASE peak.

Figures 16a and $b$ clearly demonstrate that both the output energy and the linewidth of the emission peaks of the DFB structure are considerably more responsive to changes in the pumping energy than the planar structure. The authors also demonstrated that DNA-based devices exhibited considerably better lasing characteristics than PMMA-based ones.

Balan et al. ${ }^{43}$ prepared a solid-state laser based on DNA-PVA (poly(vinyl alcohol)) doped with the Rhodamine 6G dye. They mixed 


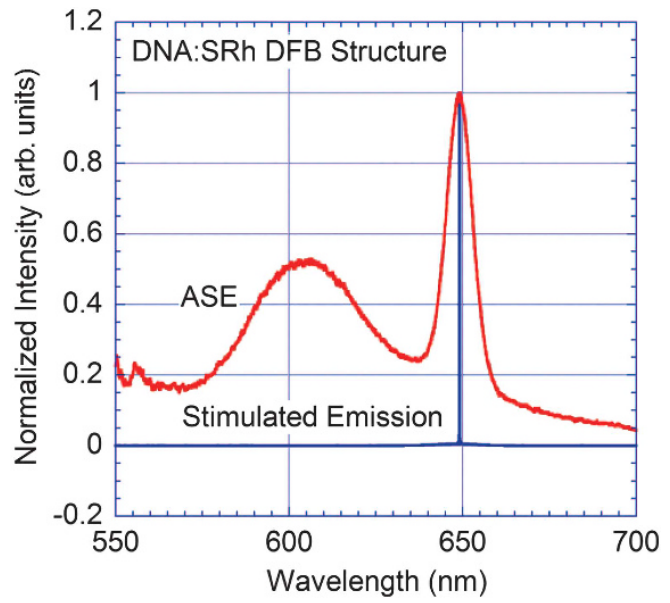

Figure 15 Amplified spontaneous and stimulated emission from DNA:SRh DFB structures ${ }^{42}$ (reprinted with permission from Yu et al., ${ }^{42}$ copyright (2007) Optical Society of America).

a
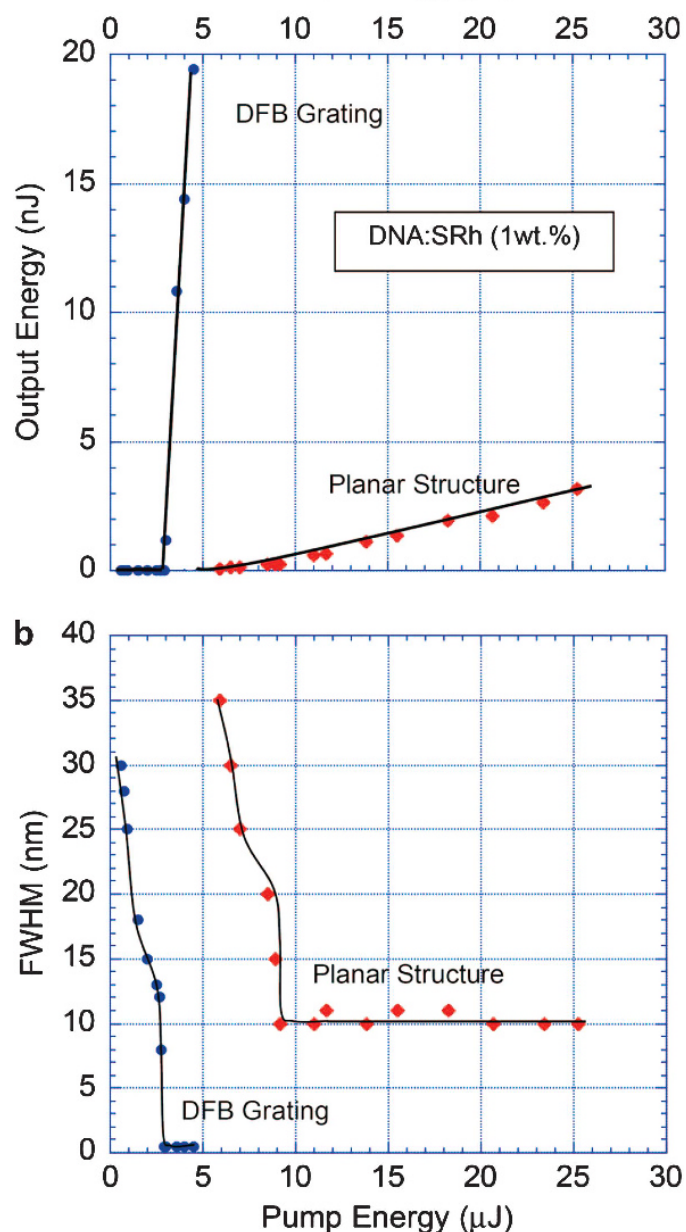

Figure 16 (a) Output energy and (b) linewidth from DNA:SRh DFB structures and thin film as a function of pump energy ${ }^{42}$ (reprinted with permission from Yu et al..,2 copyright (2007) Optical Society of America).
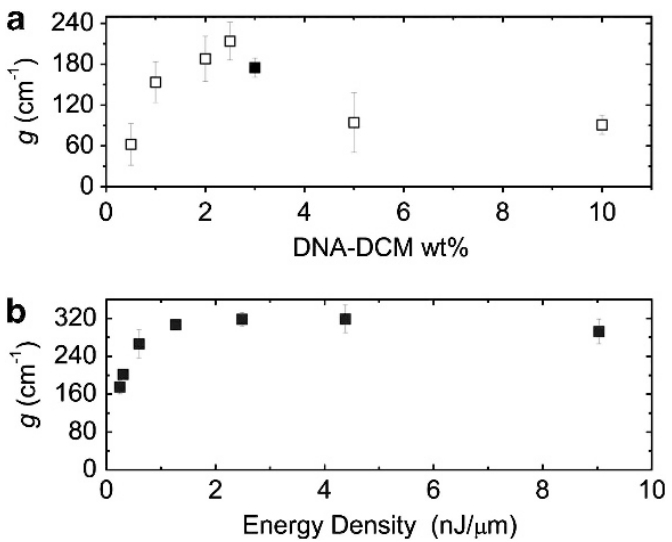

Figure 17 Optical gain coefficient $g$ plotted as a function (a) of DNA-DCM weight percentage and (b) of pump pulse energy density for DNA containing 3 wt $\%$ of DCM [solid square in (a) ${ }^{44}$ (reprinted with permission from Leonetti et al., ${ }^{44}$ copyright (2009) Optical Society of America).

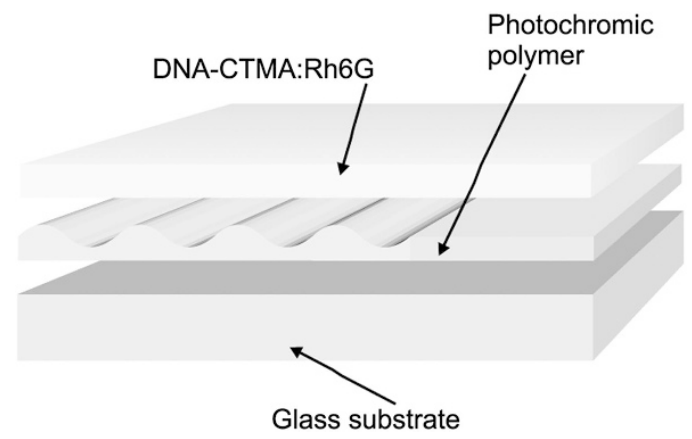

Figure 18 Schematic view of the thin film DFB laser structure prepared on a glass plate. The photochromic polymer with SRG is covered from the top by the biopolymeric matrix of DNA-CTMA containing Rh6G ${ }^{45}$ (reprinted with permission from Mysliwiec et al., ${ }^{45}$ copyright (2010) American Institute of Physics).

an aqueous solution of the DNA-Rhodamine dye with an aqueous DNA solution and prepared a thin solid film by evaporating off the water. They observed multimode laser emission from the transverse pumping of the blend film. They believed that the reflections from the lateral faces of the film resulted in a DFB. For a pump energy of $10 \mathrm{~mJ}$ per pulse, they observed a FWHM of $0.2 \mathrm{~nm}$ for the emission peak at $566 \mathrm{~nm}$. Note that this research group utilized all water-soluble ingredients. However, the distribution of the laser dye between the two polymer matrices is not known. Lopez and coworkers ${ }^{44}$ studied the optical gains of the lasing DNA-CTMA/DCM composites. They observed that an optical gain coefficient $>300 \mathrm{~cm}^{-1}$ could be obtained. Figures $17 \mathrm{a}$ and $\mathrm{b}$ show the dependence of the gain coefficient on the DCM level and on the pump energy density, respectively. The optimal amplification density was observed at $\sim 2.5$ wt $\%$ of DCM. Quenching occurred at higher concentrations. Figure $17 \mathrm{~b}$ shows that the gain coefficient saturates at $\sim 4 \mathrm{~nJ} \mu \mathrm{m}^{-2}$, and above this value, the gain value slowly decreases, most likely because of optical damage.

Recently, Mysliwiec et al. ${ }^{45}$ investigated ASE and lasing in a twolayer system composed of a DNA-CTMA/Rhodamine 6G layer superimposed on a periodic SRG (surface relief grating) structure of 


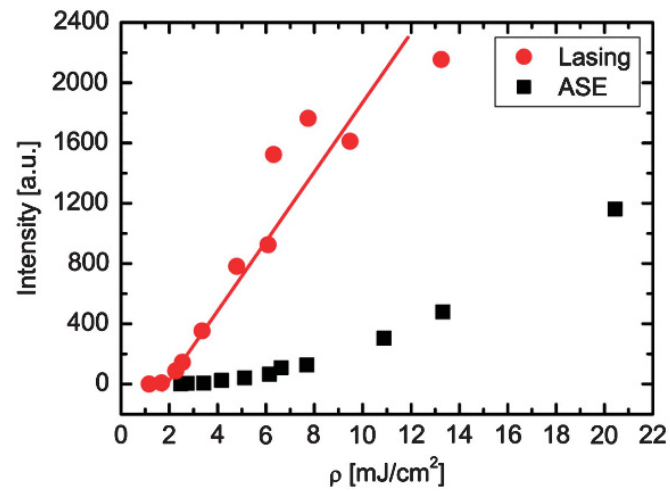

Figure 19 Peak intensities for different excitation energy densities in the case of DFB lasing and ASE. The laser threshold lies at pump energy density equal to 1.8 for DFB and $3 \mathrm{~mJ} / \mathrm{cm}^{2}$ for $A S E,{ }^{45}$ respectively (reprinted with permission from Mysliwiec et al., ${ }^{45}$ copyright (2010) American Institute of Physics).

a photochromic side chain liquid crystalline azo polymer. The twolayer hybrid lasing system is presented in Figure 18.

The FWHM for lasing was $4 \mathrm{~nm}$ compared with the value of $(9 \mathrm{~nm})$ for ASE. The emitted light signal intensity for lasing increased considerably faster than the ASE, as shown in Figure 19. The authors suggest that further optimization of the design of the device is required to achieve a lower threshold excitation energy and narrower spectral linewidth.

DNA intercalation and minor groove binding of fluorescent dyes appear to be very interesting approaches to achieving cavityless structures that provide lasing. The development of solid-state and even possibly flexible organic lasers could lead to revolutionary new laser devices that can easily be fabricated into complex structures.

\section{DNA-BASED NONLINEAR OPTICAL COMPOSITIONS}

Inorganic nonlinear optical crystals ${ }^{46}$ are widely used in many optical devices and are very important in optical communications. However, there have also been many investigations ${ }^{47,48}$ into the science and development of organic nonlinear optical crystals and polymers due to their versatility and easy processability. Grote et al. ${ }^{24}$ succeeded in preparing a DNA-CTMA thin film ( $5 \mu \mathrm{m}$ thick) containing $10 \%$ of the DR1 chromophore on an indium tin oxide-coated glass. They electrically poled the film at $50{ }^{\circ} \mathrm{C}$ with an electric field of $54 \mathrm{~V} \mu \mathrm{m}^{-1}$. They obtained an electro-optic coefficient of $2.13 \mathrm{pm} \mathrm{V}^{-1}$ at $\lambda=633$ $\mathrm{nm}$. Although they claimed that this value is comparable to the value for a PMMA film with the same concentration of DR1, they did not provide detailed experimental procedures or data. Because DNACTMA is a polyelectrolyte, it is rather difficult to determine how the substrate matrix itself and the dye molecules would respond to an external electric poling field. In other words, quantitative information on the orientation of the dipoles of the dye molecules is lacking. Very recently, Sahraoui et al. ${ }^{49}$ performed a very important study on the second- and third-harmonic generations of $\mathrm{DNA}^{-}-\mathrm{Q}^{+}$complexes with two different $\mathrm{Q}^{+}$structures, (a) and (b) in Figure 20, mixed with two electron-donor/electron-acceptor type NLO dyes, (1) and (2) in Figure 21. The NLO properties of the resulting thin films were obtained using the Maker fringes method.

The authors observed that the second-harmonic generation signals for both Dye1 and Dye2 were very weak when compared with that of

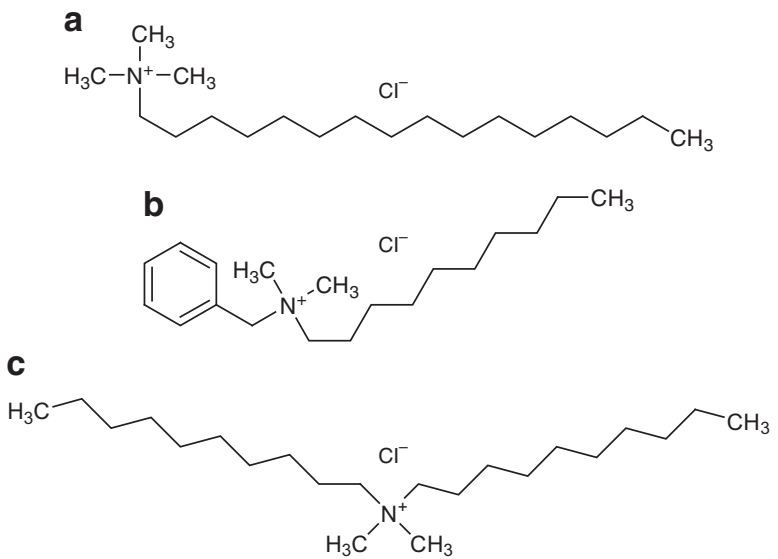

Figure 20 Surfactant structures: CTMA (a), BA (b), and DDCA (c) ${ }^{49}$ (reprinted with permission from Sahraoui et al., ${ }^{49}$ copyright (2011) American Institute of Physics).

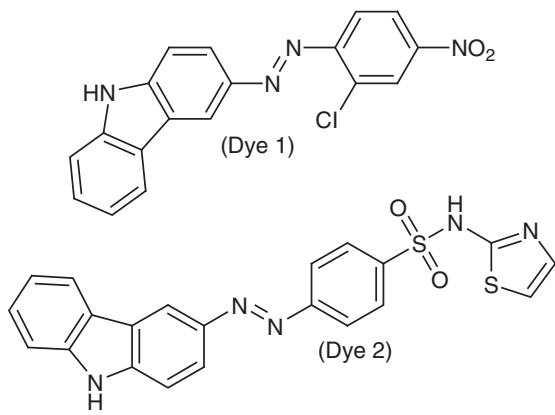

Figure 21 Chemical structures of original dyes. (1) $4-(9 \mathrm{H}-$ carbazol-3-ylazo)3-chloro-N,N-dihydroxy-aniline [Dye1], (2) 4-(9H-carbazol-3-ylazo)- Nthiazol-2-yl-benzenesulfonamide [Dye2] ${ }^{49}$ (reprinted with permission from Sahraoui et al., ${ }^{49}$ copyright (2011) American Institute of Physics).

the quartz reference, and the effective $\chi^{2}$ values were only 0.011 and $0.03 \mathrm{pm} \mathrm{V}^{-1}$, respectively. Furthermore, the values remained constant irrespective of the polarization, that is, $\mathrm{p}-\mathrm{p}$ or s-s polarization. This result indicates the absence of any orientation of the dye molecules induced by the double-helical substrate. The third-harmonic generation behavior was also the same for both polarizations. The evaluated third-order nonlinear susceptibility values are provided in Table 1. These values are significantly greater than the value for fused silica. The $\chi^{3}$ values for the DNA-DDCA/Dye1 and DNA-BA/Dye1 samples were approximately five times greater than the value reported for Dyel dispersed in a cured epoxy resin matrix. The authors attributed the higher values to a better dispersion of the dye molecules in the $\mathrm{DNA}^{-}-\mathrm{Q}^{+}$matrices. More efficient dispersion would prevent the dye molecules from forming aggregates. It is very possible that the electronic interactions between the $\pi$-systems of DNA and the dye molecules resulted in an enhanced, third-order, nonlinear optical property.

The conjecture described above is supported by the recent report of Derkowska et al. ${ }^{53}$ They studied the third-order nonlinear optical susceptibilities of the following oxazoline derivatives (see Figure 22) and their mixtures with DNA-CTMA.

The authors observed that the third-order NLO susceptibility and the linear absorption coefficient of the compounds were considerably 
Table 1 Comparison of the $\chi_{\text {elec }}^{(3)}$ values in different samples ${ }^{49}$

\begin{tabular}{|c|c|c|}
\hline Model sample & $\begin{array}{c}\text { Rentjes }^{50} \\
\chi_{\text {elec }}^{(3)}\left(\times 10^{-21} \mathrm{~m}^{2} \mathrm{~V}^{-2}\right)\end{array}$ & $\begin{array}{c}K_{a j z a r}{ }^{51,52} \\
\chi_{\text {elec }}^{(3)}\left(\times 10^{-21} \mathrm{~m}^{2} \mathrm{~V}^{-2}\right)\end{array}$ \\
\hline Fused silica & & \\
\hline Dye1/DNA-DDCA & $17.0 \pm 1.9$ & $15.0 \pm 1.0$ \\
\hline Dye1/DNA-BA & $19.0 \pm 1.8$ & $17.0 \pm 0.9$ \\
\hline Dye2/DNA-BA & $1.9 \pm 0.2$ & $1.8 \pm 0.1$ \\
\hline
\end{tabular}

Reprinted with permission from Sahraoui et al., ${ }^{49}$ copyright (2011) American Institute of Physics.

Table 2 The values of the linear absorption coefficient $(\alpha)$ and the absolute values of the third-order nonlinear optical susceptibility $\left(\chi^{(3)}\right)$ for IIIm, IIIp, IIIm-DNA-CTMA, and IIIp-DNA-CTMA dissolved in butanol (for $\left.C=1.2 \mathrm{~g} \mathrm{I}^{-1}\right)^{53}$

\begin{tabular}{lcc}
\hline & $\alpha\left(\mathrm{cm}^{-1}\right)$ & $\chi^{(3)} \times 10^{20}\left(\mathrm{~m}^{2} \mathrm{~V}^{-2}\right)$ \\
\hline IIIm & 0.88 & 0.67 \\
IIIm-DNA-CTMA & 1.08 & 0.80 \\
IIIp & 0.97 & 0.90 \\
IIIP-DA-CTMA & 1.40 & 1.17 \\
\hline
\end{tabular}

Reprinted with permission from Derkowska et al., ${ }^{53}$ copyright (2011) Elsevier.

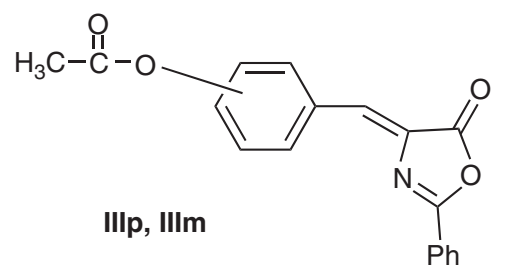

Figure 22 Chemical structure of oxazoline derivatives. IIIp, IIIm: oxazoline derivatives with acetate group at the para or meta position ${ }^{53}$ (reprinted with permission from Derkowska et al., ${ }^{53}$ copyright (2011) Elsevier).

higher when they were intercalated into the DNA-CTMA matrix, as shown in Table 2. The intercalation of dye molecules into DNACTMA must promote charge migration and NLO activities. Note that when PVA-Rhodamine 6G was mixed with DNA, reverse saturable absorption was observed near the focus, with saturable absorption behavior away from the focus. ${ }^{54}$

In relation to the topic discussed above, Walter and Geiger ${ }^{55}$ recently published an important review on how nonlinear optics can be utilized to study the electronic, vibrational, electrostatic, and chiral characteristics of DNA at its surfaces, interfaces, and also in its native state. One can obtain the electronic second-harmonic generation spectra of single- and double-stranded DNAs in different states by scanning the fundamental beam across the two-photon resonance of the $\pi-\pi^{\star}$ transition of the DNA bases at $260 \mathrm{~nm}$. In addition, a number of C-H oscillations from the $-\mathrm{CH}-,-\mathrm{CH}_{2}-$, and $-\mathrm{CH}_{3}$ groups of the DNA sugar backbone and bases can be readily monitored using vibrational sum frequency generation. Carbonyl and amine groups are also easily studied through their vibrational motions. These sources of information are crucial for tracking DNA recognition events in real time and for learning about the specific molecular kinetics. It is believed that nonlinear optical imaging will

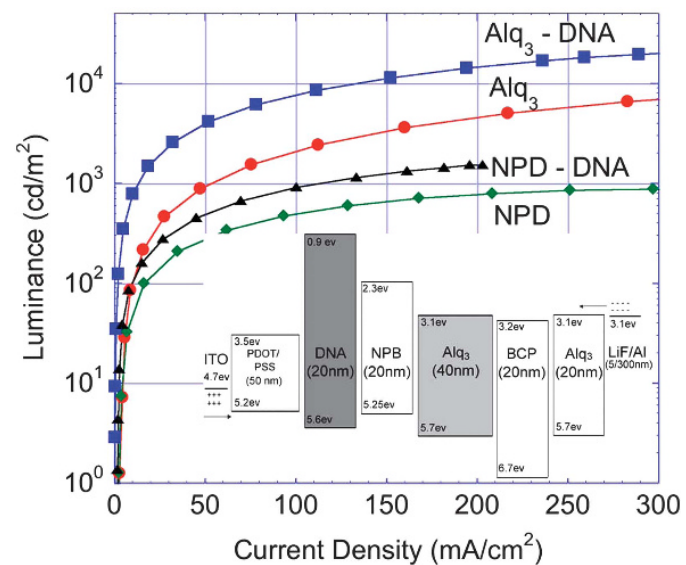

Figure 23 Luminance versus current density in green $\mathrm{Alq}_{3}$ and blue NPB EL devices with and without DNA EBL. The inset shows an energy level diagram of a green-emitting $\left(\mathrm{Alq}_{3}\right)$ DNA BioLED structure ${ }^{56}$ (reprinted with permission from Hagen et al., ${ }^{56}$ copyright (2006) American Institute of Physics).

become a very important tool for probing the molecular interactions of DNA, including recognition.

\section{LIGHT-EMITTING DIODES BASED ON DNA}

Organic light-emitting diodes (OLEDs) and organic PLEDs (polymer light-emitting diodes) are attracting a considerable amount of interest not only in academia but also in industry because of the advantages of using organic materials in LED applications. Organic materials are potentially less costly, easier to process into large-area light panels, and there also exists the possibility of developing flexible substrates based on them.

Hagen et al. ${ }^{56}$ achieved enhanced EL (electroluminescent) efficiency using DNA-CTMA as an electron-blocking layer, which does not interfere with the transport of holes. Consequently, DNA-CTMA promotes the formation of excitons. The authors demonstrated enhanced EL by fabricating green $\left(\mathrm{Alq}_{3}\right)$ and blue (NPB) OLEDs with DNA-CTMA. They obtained maximum luminous efficiencies of 8.2 and $0.8 \mathrm{~cd} \mathrm{~A}^{-1}$ for the green and blue OLEDs, respectively.

Figure 23 compares the luminous performances of the blue and green LEDs with and without the DNA-CTMA electron-blocking layer. At a current density of $200 \mathrm{~mA} \mathrm{~cm}^{-2}$, the green light-emitting device achieves $15000 \mathrm{~cd} \mathrm{~m}^{-2}$ and the blue light-emitting device achieves $1500 \mathrm{~cd} \mathrm{~m}^{-2}$. The devices without the DNA-CTMA layer achieve values of 4500 and $800 \mathrm{~cd} \mathrm{~m}^{-2}$, respectively. The fabrication of natural DNA-containing OLEDs was recently described in detail by Gomez et al. ${ }^{57}$ Earlier, the Japanese group lead by Hirata et al. ${ }^{58}$ constructed OLED devices containing a DNA-CTMA layer, which they utilized for a study of the electrical properties of the layer. Their conclusion was that the DNA-CTMA layer preferentially transports holes rather than electrons. Recently, the same research group ${ }^{18}$ reported that the maximum brightness they could obtain was nearly $100000 \mathrm{~cd} \mathrm{~m}^{-2}$ at $13 \mathrm{~V}$, with a maximum current efficiency of $\sim 90 \mathrm{~cd} \mathrm{~A}^{-1}$ and a luminous efficiency of $55 \mathrm{~lm} \mathrm{~W}^{-1}$ at $5 \mathrm{~V}$. These values are very remarkable. However, it should be mentioned that the experimental details were not described.

We took a slightly different approach for utilizing DNA in phosphorescent OLED structures. Because $\mathrm{Cz}$ derivatives have long been employed as hosts of phosphorescent metal complexes, such as $\operatorname{Ir}(\mathrm{Cz}-\mathrm{ppy})_{3}$, in OLED devices, we modified the chemical structure of 


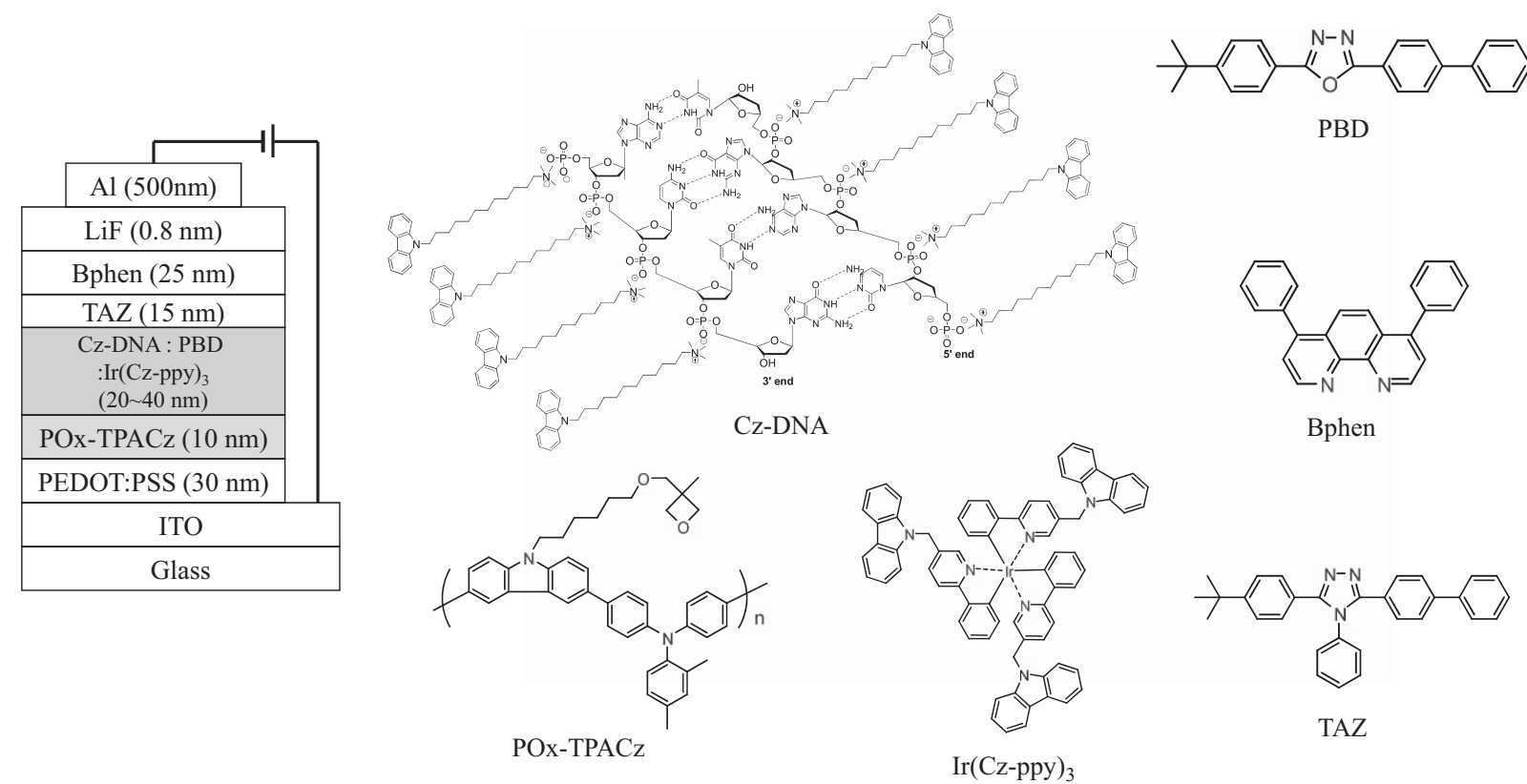

POX-TPACz

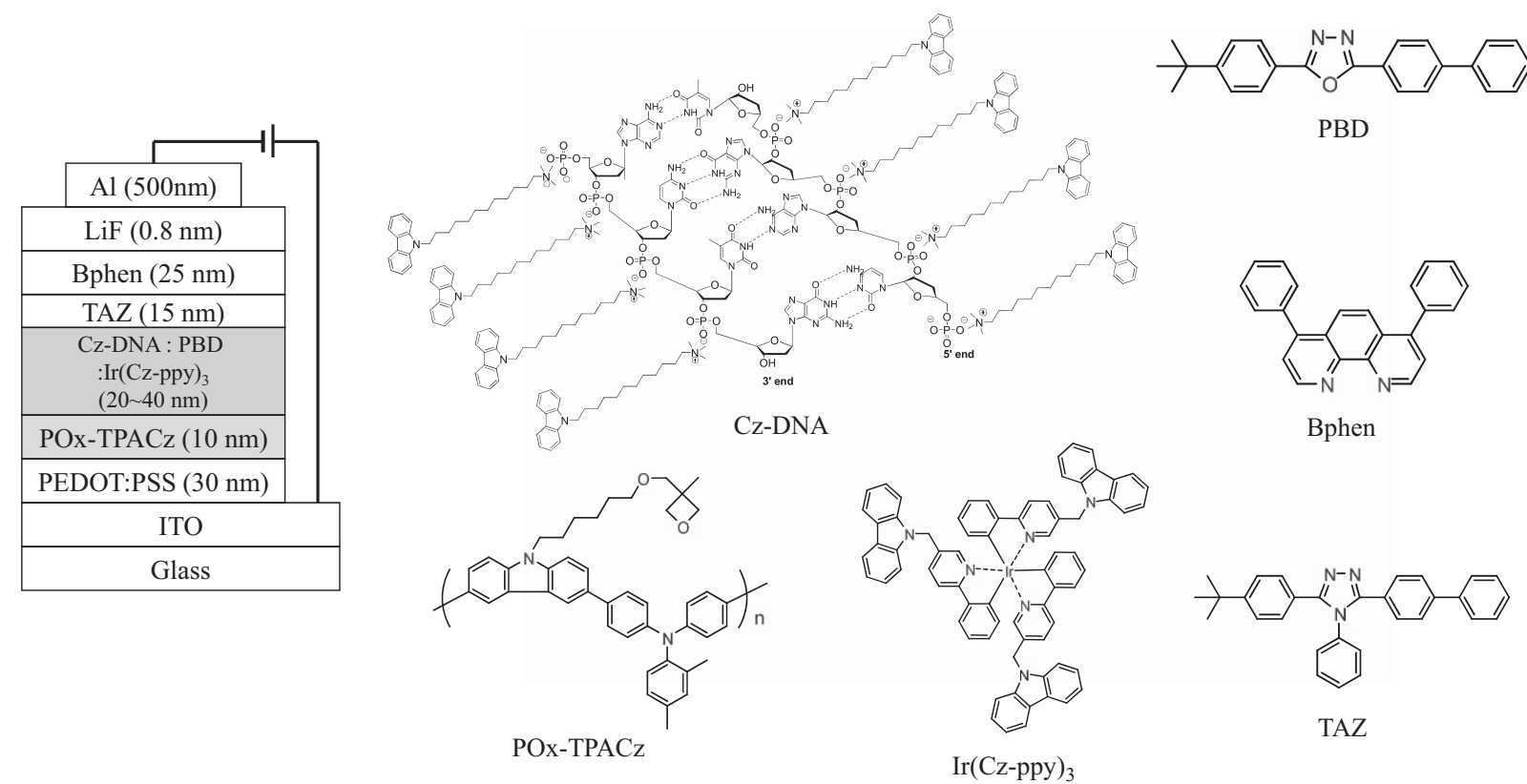

Figure 24 Molecular structures of Cz-DNA, POx-TPACz, Ir(Cz-ppy)3, PBD, Bphen, and TAZ. The device configuration of the electrophosphorescent PLED. *PBD: 2-(biphenyl-4-yl)-5-(4-tert-butylphenyl)-1,3,4-oxadiazole, Bphen: 4,7-diphenyl-1,10-phenanthroline, TAZ: 3-(biphenyl-4-yl)-5-(4-tert-butylphenyl)-4phenyl-4H-1,2,4-triazole ${ }^{59}$ (reprinted with permission from Cho et al., ${ }^{59}$ copyright (2010) Wiley Periodicals, Inc.). A full color version of this figure is available at Polymer Journal online.

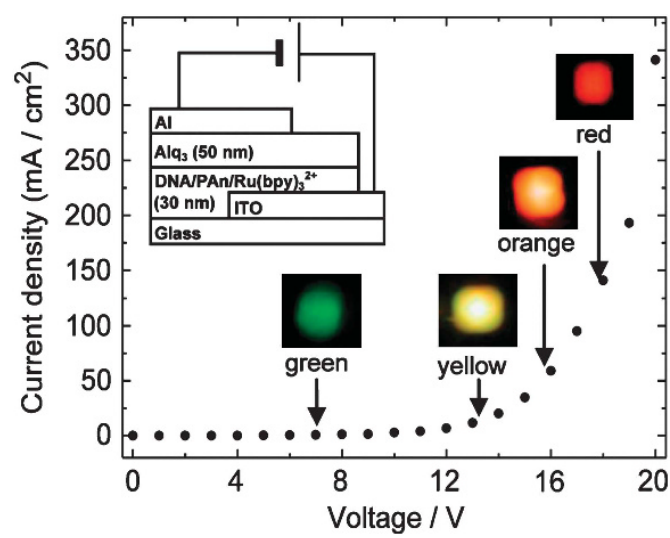

Figure $25 \mathrm{I}-\mathrm{V}$ characteristics and photographs of OLEDs (the inset shows a schematic of the OLED configuration) ${ }^{60}$ (reprinted with permission from Nakamura et al., ${ }^{60}$ copyright (2010) American Institute of Physics).

the CTMA part of DNA-CTMA and attached the Cz moiety at the end of the dodecyl alkyl group (Cz-DNA), ${ }^{59}$ whose chemical structure is shown below. A photocrosslinkable polymer was utilized as a buffer layer (Figure 24).

As the structure of the device in Figure 24 shows, the Cz-DNA was doped with $\operatorname{Ir}(\mathrm{Cz}-\mathrm{ppy})_{3}$. It was observed that when the electrontransport compound PBD (5,4-tert-butylphenyl-1,3,4-oxadiazole) was mixed with the phosphorescent light-emitting layer, the device performance was significantly improved. The maximum luminance of a PBD containing device was $1135 \mathrm{~cd} \mathrm{~m}^{-2}$ compared with the value of only $244 \mathrm{~cd} \mathrm{~m}^{-2}$ for the device without $\mathrm{PBD}$. The maximum luminous efficiencies were 3.41 and $0.74 \mathrm{~cd} \mathrm{~A}^{-1}$, respectively, for the two devices. Device optimization may be able to improve the performance even further. A very interesting report was recently published by Kobayashi and coworkers, ${ }^{60}$ who fabricated a OLED device composed of a DNA/polyaniline $/ \mathrm{Ru}(\mathrm{bpy})_{3}{ }^{2+}$ complex and $\mathrm{Alq}_{3}$ that exhibited a voltage-controlled color tunability. Figure 25 presents a schematic representation of the structure of the device and the dependence of the emitted light color on the input field. As the field is increased, the color of the light emitted by the OLED device changes from green to red through the emission of yellow and orange colors.

Although DNA-based OLEDs are undoubtedly very interesting and provide us with many scientific and practical questions, it should, however, be remembered that DNA, DNA-CTMA, and the other DNA-containing compositions are essentially polyelectrolytes. Because these compounds are polyelectrolytes, they are supposed to have a sensitive response to an external field; their DNA chains should undergo conformational changes more readily in the electric field, which may even lead to their partial migration. This behavior could generate diverse problems associated with the long-term stability of the device performance. Note that DNA chains are extremely hydrophilic, and the degree of removal of water molecules from the DNA-containing layers is expected to influence the device performance. Controlling the level of water molecules attached to the DNA chains appears to be a critical factor for obtaining reproducible OLED devices with temporal stability.

\section{PHOTOVOLTAICS OF DNA-BASED SOLAR CELLS}

The photovoltaic process is the reverse of the light-emitting process of OLEDs, which was discussed above. Therefore, it is expected that DNA-based photovoltaic devices can be fabricated and that we can expect reasonably favorable performance efficiencies.

Several years ago, Bandyopadhyay et al. ${ }^{61}$ examined the feasibility of using DNA (calf-thymus) and adenine as solid-state electrolytes in a dye-sensitized $\mathrm{TiO}_{2}$ solar cell. The authors used Rose Bengal for the 


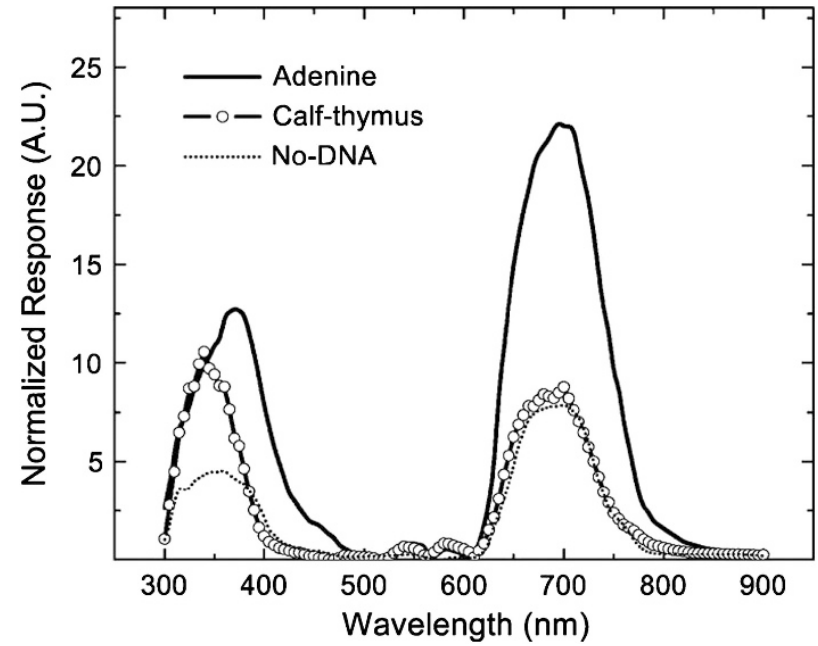

Figure 26 Photovoltaic response against the wavelength of the monochromatic light source from 300 to $900 \mathrm{~nm}$ under open-circuit conditions $^{61}$ (reprinted with permission from Bandyopadhyay et al., 61 copyright (2007) American Institute of Physics).

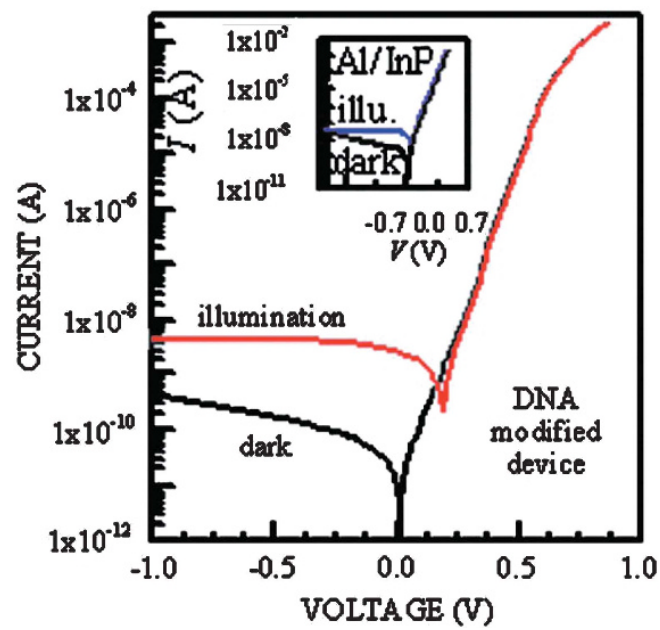

Figure 27 Current-voltage characteristics of Al/DNA/p-InP Schottky devices under dark and illuminated conditions at room temperature. Inset shows the current-voltage characteristics of the reference $(\mathrm{Al} / \mathrm{p}-\mathrm{InP})$ diode under illumination ${ }^{63}$ (reprinted with permission from Gullu et al., ${ }^{63}$ copyright (2008) American Institute of Physics).

dye sensitization. Figure 26 compares the photovoltaic responses of three different devices with or without DNA. The open-circuit voltage was the highest for the device with adenine, $0.7 \mathrm{~V}$, and the one with DNA was next, $0.35 \mathrm{~V}$. The DNA device exhibited poor stability, which was attributed to a possible destruction of the double-stranded helical structure under illumination. The dye-sensitized $\mathrm{TiO}_{2}$ solar cells are generally called Gratzel cells ${ }^{62}$ after their pioneer.

Gullu et al. ${ }^{63}$ and Kolachure and Jin ${ }^{64}$ separately fabricated an Al/DNA-CTMA/p-InP Schottky junction and an ITO/DNA-CTMA/ P3HT(PCBM)/Al bulk heterojunction solar cell. The first group ${ }^{63}$ observed that the DNA-based sandwich device exhibited excellent rectifying behavior. The reverse bias current of the Al/DNA-CTMA/ p-InP solar cell increased on illumination considerably more than
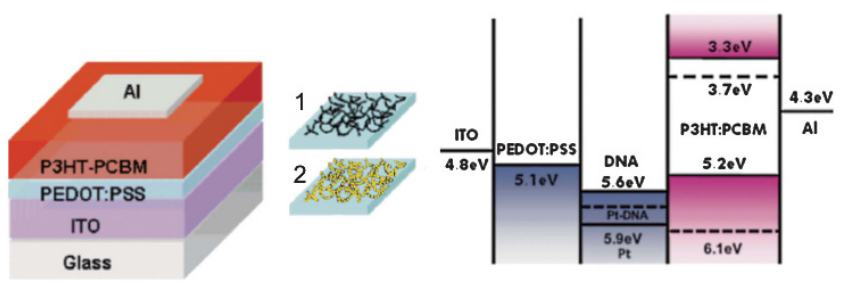

Figure 28 Schematic of device showing the structure when DNA (device 1) or DNA-Pt (device 2) is incorporated ${ }^{65}$ (reproduced with permission from Yengel et al., ${ }^{65}$ copyright (2009) SPIE.

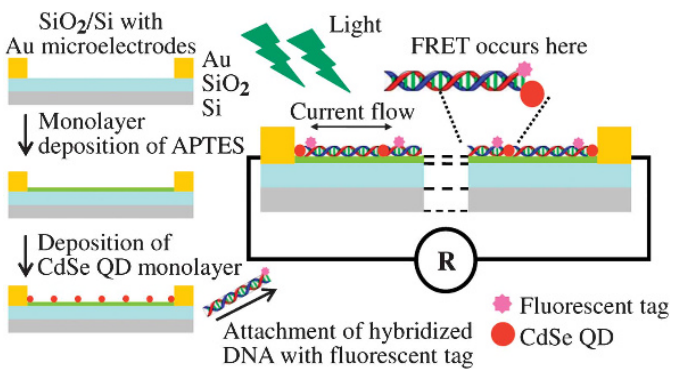

Figure 29 Schematic diagram showing the preparation of the proposed sensing platform 67 (reprinted with permission from Qi et al., ${ }^{67}$ copyright (2009) American Institute of Physics).

that of the $\mathrm{Al} / \mathrm{p}-\mathrm{In}$ diode. This result indicates that more carriers are photogenerated in the DNA-modified junction (Figure 27).

The maximum open-circuit voltage and the short-circuit current value obtained for the device were $0.20 \mathrm{~V}$ and $2.8 \mathrm{nA}$, respectively, at $150 \mathrm{~lx}$ light intensity, which are compared with the values, $0.06 \mathrm{~V}$ and $26.0 \mathrm{nA}$, for the device without DNA. The second group ${ }^{64}$ successfully replaced the commonly used hole injection layer of PEDOT:PSS with the DNA-CTMA layer in the fabrication of solar cells. Their solar cells exhibited rectifying behavior in the dark and solar energy conversion when illuminated by a $300-\mathrm{W}$ projector lamp. As the authors mentioned, a further detailed characterization of such devices is necessary before we can judge the usefulness of DNACTMA as the hole injection layer in solid-state solar cells.

In connection to the studies described above, Yengel et al. ${ }^{65}$ reported an interesting study on solar cells containing $\lambda$-DNA and DNA/Pt layers, whose structures are shown in Figure 28.

The authors formed DNA/Pt through the chemical reduction of a DNA-Pt complex using dimethylaminoborane. They observed that the device containing only the DNA layer exhibited a $12 \%$ increase in the power conversion efficiency, whereas that containing DNA and a DNA-Pt layer exhibited a $25 \%$ improvement. This improvement can be attributed to the hole-transporting property of DNA and its reduction of the recombination losses of the carriers. It is believed that the DNA-Pt composite layer improves the mobility of the carriers, especially that of electrons, through the poorly conducting DNA layer. However, the power conversion efficiency of even the best device was very low, only $0.0105 \%$. There is no doubt that DNA can be advantageously utilized in OLEDs and photovoltaic devices; nevertheless, further systematic studies are required to achieve this goal. The increase in the use of DNA in different solar cells can be observed in recent publications by Kumar and Duff ${ }^{66}$ and by Wong and coworkers. ${ }^{67}$ Kumar and Duff ${ }^{66}$ demonstrated a very interesting 


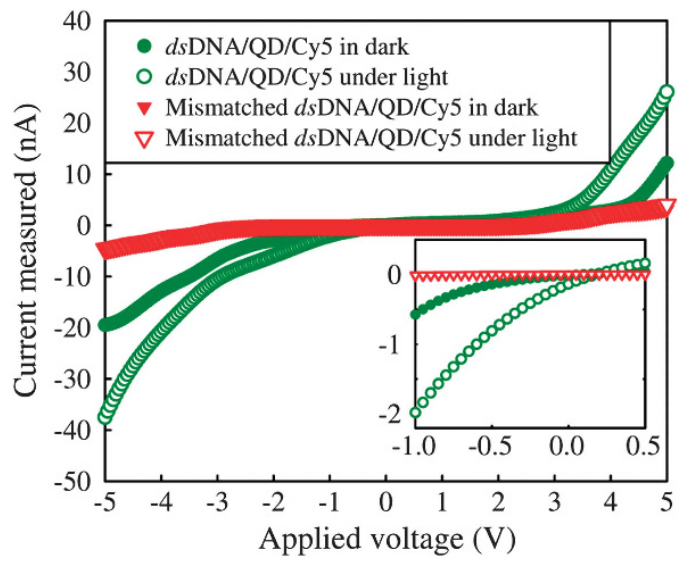

Figure $30 \mathrm{I}-V$ characteristics of a device with a QD monolayer linked by hybridized dsDNA with complete complementarity (denoted as dsDNA/QD/ Cy5), and a device with a QD monolayer linked by partially mismatched hybridized DNAs (denoted as mismatched dsDNA/QD/Cy5), under darkness and illumination with a green laser light. Inset: Expanded I-V characteristics $^{67}$ (reprinted with permission from Qi et al., ${ }^{67}$ copyright (2009) American Institute of Physics). proof-of-concept model of supramolecular artificial light harvesting complexes based on a DNA-engineered protein. The novelty of this work lies in self-assembly of the device components in a predetermined manner at the desired locations, which is possible because the DNA functions as a supramolecular scaffold. Wong's group $^{67}$ designed and fabricated a special DNA sensing platform that exhibited both FRET and the photovoltaic effect, which was based on a network of DNA and a quantum dot (CdSe;QD) hybrid system; see Figure 29.

When a complementary DNA sequence is attached to the hybrid molecular switch, both FRET and a photovoltaic effect are observed simultaneously. However, if the base sequences of the DNA are mismatched, the charge carriers within the DNA molecules are expected to be localized, which leads to a large reduction in the charge transfer efficiency. The corresponding photovoltaic effect is also weakened (Figure 30).

\section{CONCLUSIONS AND PERSPECTIVES}

Although the fluorescence properties of many modified DNAs were discussed in the early part of this article, a clear understanding of the fluorescence of natural DNA itself may cast light on the nature of the

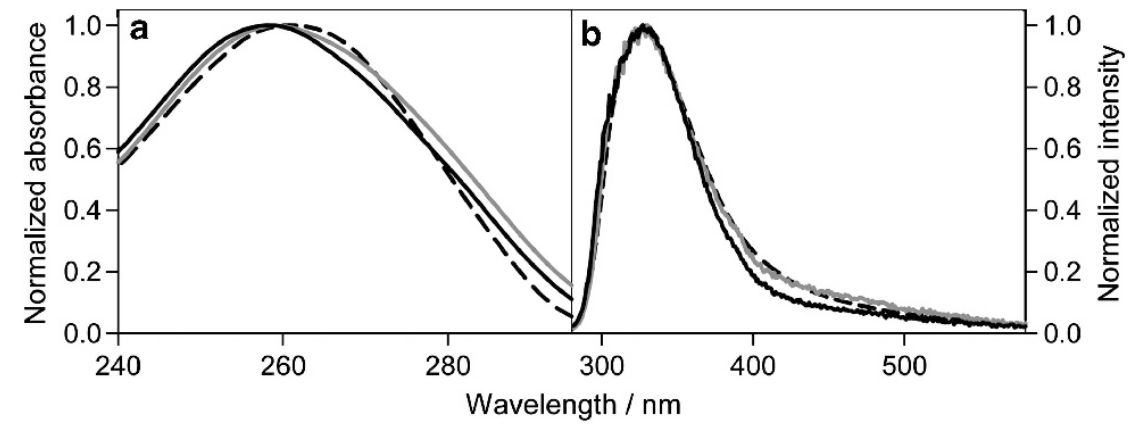

Figure 31 (a) Normalized steady-state absorption and (b) fluorescence spectra of DNA in pure water (gray) and in phosphate buffer (black). Excitation wavelength: $267 \mathrm{~nm}$. The spectra of the stoichiometric mixture of monomers (58\% of dAMP and TMP, $42 \%$ of dGMP and dCMP) in water are shown as dashes $^{68}$ (reprinted with permission from Vaya et al., 68 copyright (2010) American Chemical Society).

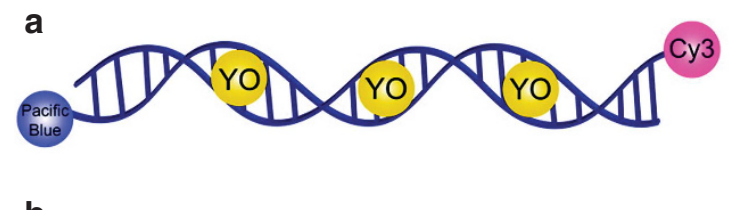

b

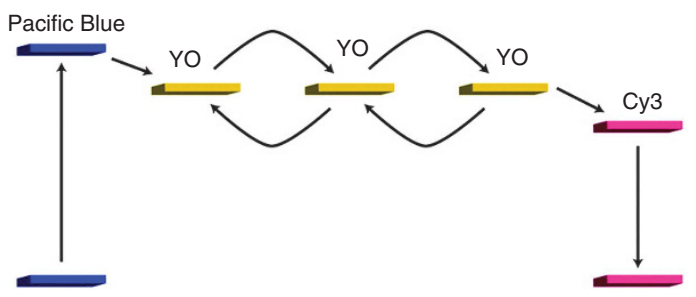

C<smiles>CN(C)CCN1CC=CC(=Cc2oc3ccccc3[n+]2C)C1=O</smiles>
Pacific Blue<smiles>COCCCN1/C(=C\C=C\C2=[N+](CCCO)c3ccccc3C2(C)C)C(C)(C)c2ccccc21</smiles>

Figure 32. (a) Schematic representation of the multichromophoric DNA wire with attached Pacific Blue (injector) and Cy3 (reporter) and intercalated YO. (b) Corresponding schematic energy level diagram, showing the diffusive energy migration in the YO section of the wire. (c) Structures of Pacific Blue, YO-PRO-1, and Cy3, the three chromophores used in the construction of the photonic wire ${ }^{70}$ (reprinted with permission from Hannestad et al.. ${ }^{70}$ copyright (2008) American Chemical Society). 

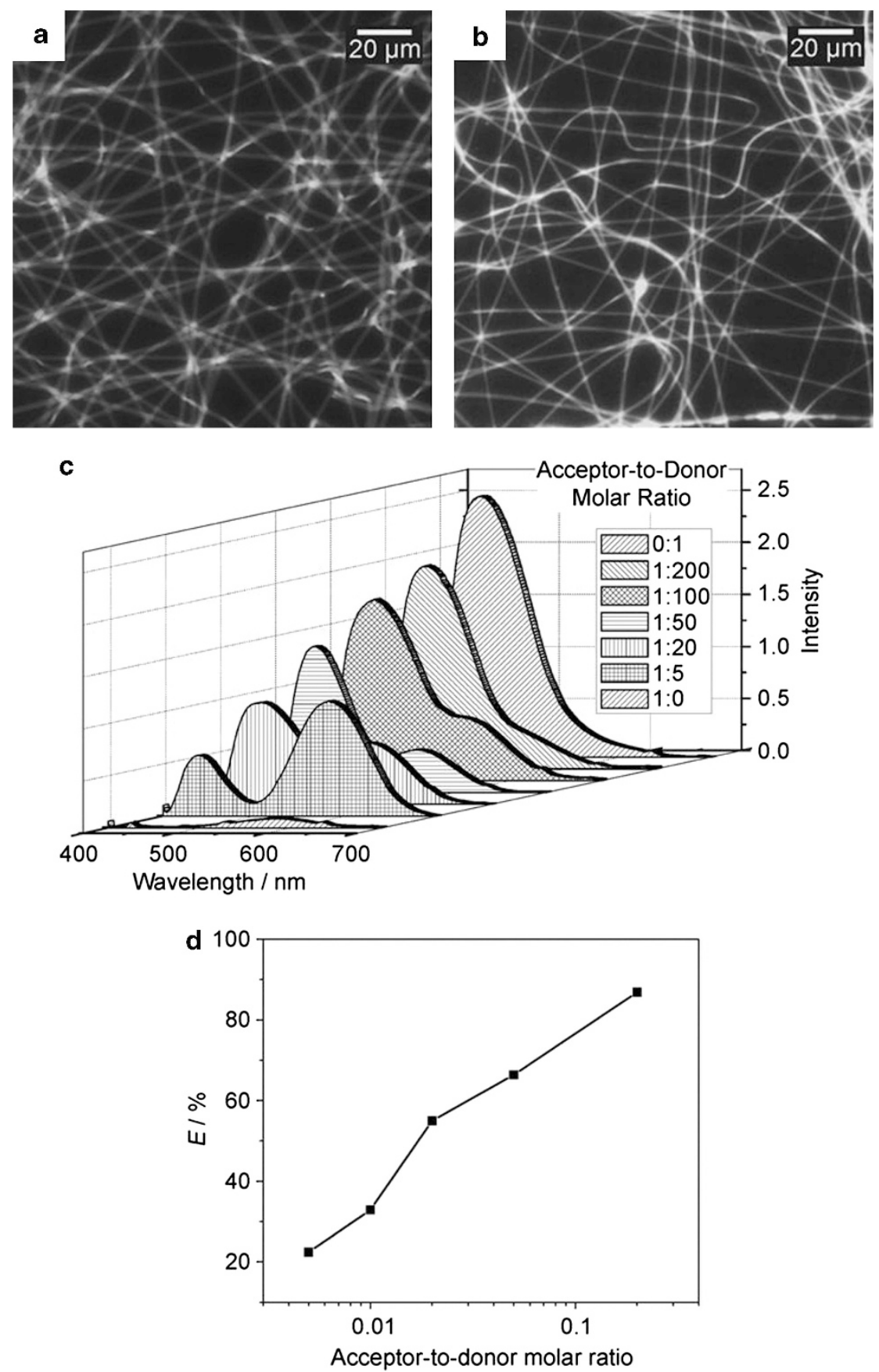

Figure 33 Fluorescence microscopy images of (a) electrospun nanofibers of DNA-CTMA-Cm102 (donor) and (b) DNA-CTMA-Cm102-Hemi22 with an acceptor-to-donor ratio of 1:5. (c) Quenching curves of multiple-dye-doped DNA-CTMA nanofibers with increasing acceptor concentration $\left(\lambda_{\text {ex }}=388 \mathrm{~nm}\right)$. In all cases, the $\mathrm{Cm} 102$ donor concentration is $1.17 \%(\mathrm{w} / \mathrm{w})$ relative to DNA. From left to right, the molar ratio of acceptor and donor varied from $1: 5$ to 1:200. The concentrations of the Hemi22 acceptor in the 1:5 sample and in the acceptor-only sample (1:0) are identical. (d) FRET efficiency plotted against acceptor-to-donor molar ratio ${ }^{71}$ (reproduced with permission from Ner et al., ${ }^{71}$ copyright (2009) Wiley-VCH Verlag GmbH \& Co., KGaA).

long-lived excited states and excitation energy transfer among the neighboring chromophores in DNA, which must be closely related to conformational disorder of the long duplex chains. Recently, Vaya et $a l^{68}$ and Markovitsi et al. ${ }^{69}$ reported on the fluorescence characteristics of natural DNA. Both groups observed that the fluorescence decay of DNA is very long, with $98 \%$ of the photons being emitted for longer than 10 ps.
Figure 31a shows the steady-state absorption and (b) fluorescence spectra of DNA. The fluorescence spectra were obtained at the excitation wavelength of $267 \mathrm{~nm}$, which corresponds to the absorption maximum. The emission maximum is observed at $327 \mathrm{~nm}$. The fluorescence quantum yield was very low, $\sim 2-3 \times 10^{-4}$. Despite this low fluorescence quantum yield for DNA, it is expected that the fluorescence of modified DNAs will be greatly influenced by the long 

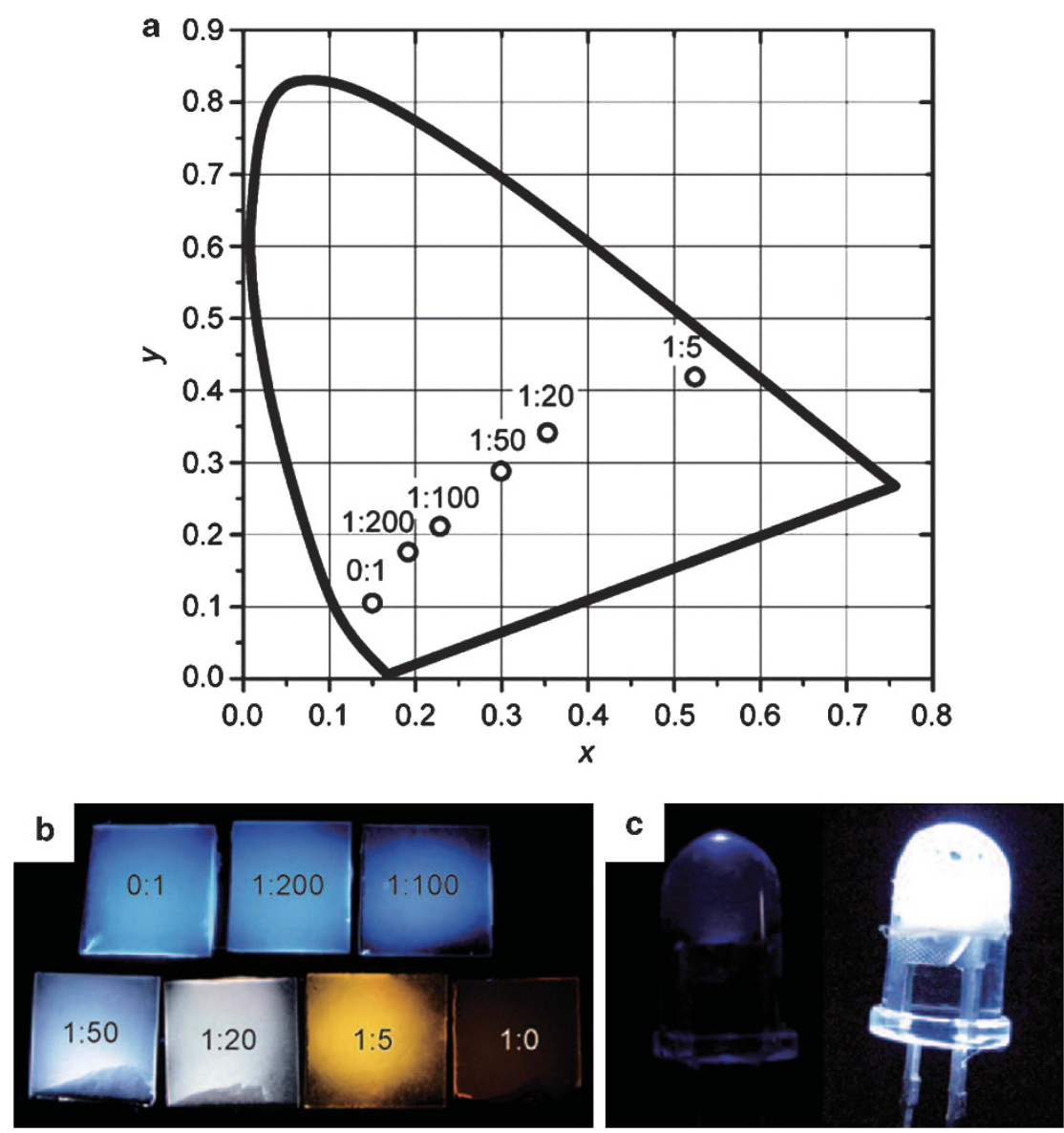

Figure 34 (a) Chromaticity parameters of dye-doped DNA-CTMA nanofibers (circles) illuminated with UV light $\left(\lambda_{\mathrm{ex}}=365 \mathrm{~nm}\right)$. For sample labeling, see Figure 33. (b) Digital photograph of luminescent nanofiber meshes deposited on glass and illuminated at $365 \mathrm{~nm}$ with a UV lamp. The acceptor-to-donor molar ratios are indicated. (c) In all, 400-nm UV LEDs without (left) and with white-light-emitting DNA nanofiber coating (right) ${ }^{71}$ (reproduced with permission from Ner et al., ${ }^{71}$ copyright (2009) Wiley-VCH Verlag GmbH \& Co., KGaA).

fluorescence lifetime of the original DNA chains. In short, gaining an understanding of the photophysics of DNA still remains one of the most important challenges in this field and will be the subject of future detailed studies. It is hoped that future studies will eventually lead to useful photophysical and photochemical applications of many self-assembled nanoscale architectures formed through molecular recognition and templates based on DNA and modified DNAs. Albinsson and coworkers ${ }^{70}$ constructed a self-assembled DNA-based photonic wire that transported excitation energy over $20 \mathrm{~nm}$, which was possible via a sequential FRET process between well-designed chromophore pairs. The schematic representation of their photonic wire, the chemical structures incorporated therein, and the sequence of excited energy transfer in the wire can be observed in Figure 32.

A different approach was taken by Sotzing's group ${ }^{71}$ to fabricate a electrospun DNA-CTMA fiber doped with the coumarin 102 acceptor and the 4-(4-dimethylaminostyryl)-1-dodecylpyridinium bromide donor. The average fiber diameter was $300 \mathrm{~nm}$. The authors observed that by varying the acceptor-to-donor molar ratio, they could continuously change the wavelength of the emitted light from blue to orange through pure white. Their results are shown in Figures 33 and 34 .
This research clearly demonstrated that the DNA-CTMA nanofibers are an efficient matrix for a multistep FRET. Another highly efficient DNA-based photonic wire was fabricated by Su et al. ${ }^{17}$ by using three different dyes doped into DNA and pyrrole-imidazole polyamides. They observed that energy transfer over 80 base pairs of the DNA chain $(\sim 27 \mathrm{~nm})$ could be achieved using this approach. A schematic representation of their approach is provided in Figure 35.

Polyamides were able to augment the energy transfer process via efficient FRET. Polyamides bind to the minor groove of dsDNA, and they exhibit a high-binding affinity and specificity to the 6-10 base pair sequences.

These approaches and findings are expected to lead to novel methods of constructing complicated three-dimensional photonic arrays and circuitries. Furthermore, efficient light harvesting materials are expected to be developed based on the science of DNA self-assembly for achieving long-distance energy transfer. The work by Armitage and coworkers ${ }^{72,73}$ on supramolecular complexes composed of a branched template and intercalating fluorophores provides us with an interesting approach for biodetection and bioimaging.

NLO and OLED applications of DNAs, especially of DNA-CTMA, are definitely very attractive due to the excellent properties of DNA, 
a

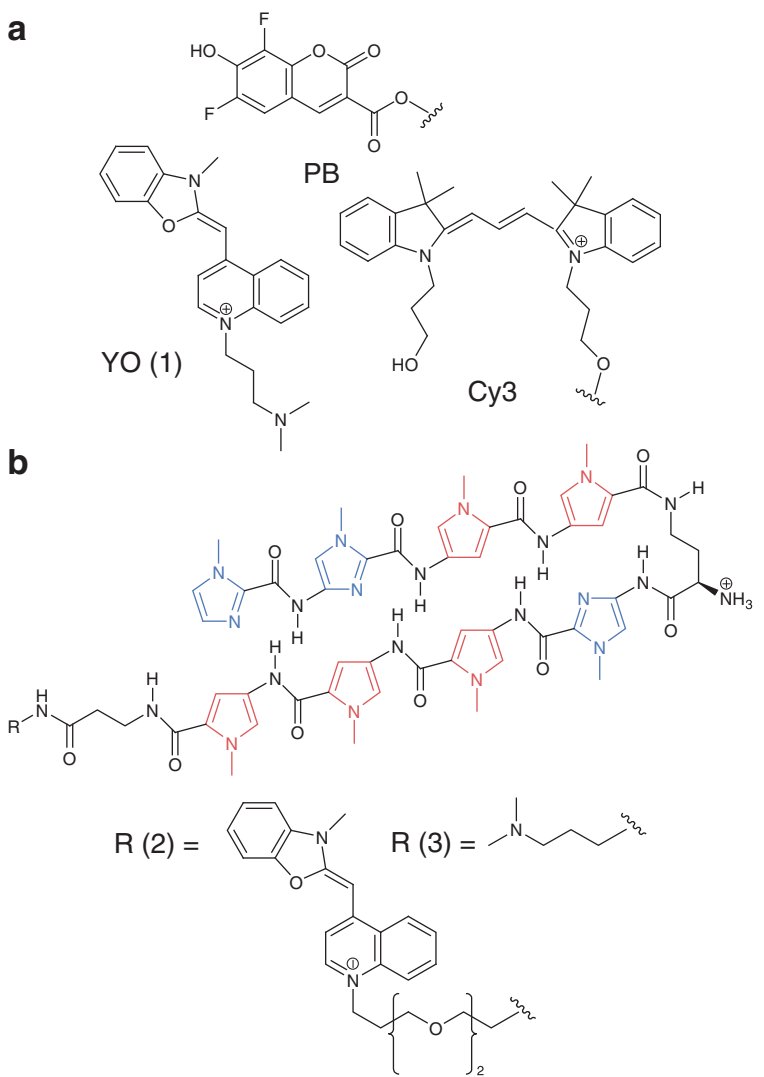

c 5'PB-TCG TTA GCA TAT ATG GAC ATA

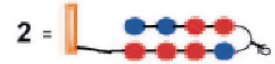

AGC AAT CGT ATA TAC CTG TAT - Cy3 $5^{\prime}$

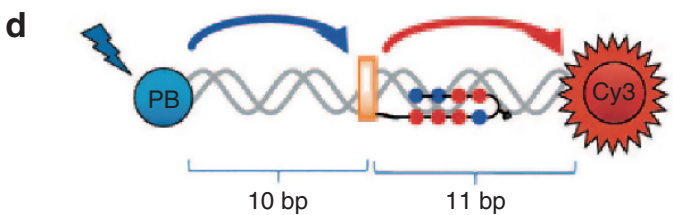

Figure 35 (a) Chemical structures of the fluorophores PB (injector), Cy3 (reporter), and YO (1). (b) Chemical structures of PAs 2 and 3. (c) Structural representation of the exemplar DNA-based photonic wire 2@DNA21. The structure of PA 2 is represented as filled blue circles for imidazole $(\mathrm{Im})$ building blocks whereas filled red circles represent pyrrole (Py) building blocks.*2@DNA21, where @ denotes the addition of 2 to DNA21. (d) Schematic representation of 2@DNA21. The interfluorophore PB-YO distance is $\sim 10$ base pairs $(\sim 3.4 \mathrm{~nm})$ whereas the interfluorophore YO-Cy3 is $\sim 11$ base pairs $(\sim 3.7 \mathrm{~nm})^{17}$ (reproduced with permission from Su et al., ${ }^{17}$ copyright (2011) Wiley-VCH Verlag GmbH \& Co., KGaA)

such as good temperature stability, a wide HOMO/LUMO band-gap, low optical absorption and propagation, low optical scattering loss, and mechanical robustness. Quoting what Steckl et al..$^{18}$ recently mentioned, DNA may be reborn as a 'molecule of light.' However, this quote must be accompanied by the warning that DNA is a hygroscopic organic polymer, and consequently, it cannot be used in extreme conditions. It is unarguable that there is considerable science that we can learn from DNA, which can lead to the development of novel ideas, new materials, and innovative new technologies. The science of DNA is opening up a new horizon in the science and development of new optical materials for various applications. The book 'Materials Science of DNA', which was recently edited and published by Jin and Grote, ${ }^{74}$ provides abundant information on the photonic properties and other applications of natural and modified DNAs.

\section{ACKNOWLEDGEMENTS}

This work was supported by the Basic Science Research Program through the National Research Foundation of Korea (NRF) funded by the Ministry of Education, Science and Technology (2010-0013225), for which Y-W Kwon is thankful. We appreciate the constructive comments made by Professor Chang Hoon Lee and Dr Eui-Kwan Koh to this article. We congratulate the Society of Polymer Science, Japan, for the 60th anniversary of its foundation.

1 Seeman, N. C. Nanomaterials based on DNA. Annu. Rev. Biochem. 79, 65-87 (2010).

2 Lewis, F. D. DNA molecular photonics. Photochem. Photobio 81, 65-72 (2005).

3 Guo, X., Gorodetsky, A. A., Hone, J., Barton, J. K. \& Nuckolls, C. Conductivity of a single DNA duplex bridging a carbon nanotube gap. Nat. Nanotech. 3, 163-167 (2008).

4 Yoo, K. H., Ha, D. H., Lee, J. O., Park, J. W., Kim, J., Kim, J. J., Lee, H. Y., Kawai, T. \& Choi, H. Y. Electrical conduction through poly(dA)-poly(dT) and poly(dG)-poly(dC) DNA molecules. Phys. Rev. Lett. 87, 198102 (2001)

5 Roy, S., Vedala, H., Roy, A. D., Kim, D. H., Doud, M., Mathee, K., Shin, H. K., Shimamoto, N., Prasad, V. \& Choi, W. B. Direct electrical measurements on singlemolecule genomic DNA using single-walled carbon nanotubes. Nano. Lett. 8, 26-30 (2008).

6 Shapir, E., Cohen, H., Calzolari, A., Cavazzoni, C., Ryndyk, D. A., Cuniberti, G., Kotlyar, A., Di Felice, R. \& Porath, D. Electronic structure of single DNA molecules resolved by transverse scanning tunnelling spectroscopy. Nat. Mater. 7, 68-74 (2008).

7 Lee, C. H., Kwon, Y. -W. \& Jin, J. -I. in Materials Science of DNA. (eds Jin, J. I. \& Grote, J. G.) 121-162 (CRC Press, Boca Ranton, 2012).

8 Lee, C. H., Do, E. D., Kwon, Y. -W., Choi, D. H., Jin, J. -I., Oh, D. K., Nishide, H. \& Kurata, T. Magnetic properties of natural and modified DNAs. Nonlinear Opt. Quantum Opt 35, 165-174 (2006)

9 Lee, C. H., Kwon, Y. -W., Do, E. D., Choi, D. H., Jin, J. -I., Oh, D. K. \& Kim, J. Electron magnetic resonance and SQUID measurement study of natural A-DNA in dry state. Phys. Rev. B 73, 224417 (2006).

10 Kwon, Y. -W., Lee, C. H., Do, E. D., Jung, K. M., Choi, D. H., Jin, J. -I. \& Oh, D. K. Photomagnetism of A-DNAs intercalated with photoresponsive molecules. Mol. Cryst. Liq. Cryst. 472, 727-732 (2007).

11 Kwon, Y. -W., Lee, C. H., Do, E. D., Choi, D. H., Jin, J. -I., Kang, J. S. \& Koh, E. K. Hydration effect on the intrinsic magnetism of natural deoxyribonucleic acid as studied by EMR spectroscopy and SQUID measurements. Bull. Korean Chem. Soc. 29, 1233-1242 (2008)

12 Kwon, Y. -W., Lee, C. H., Choi, D. H., Jin, J. -I., Koh, E. K. \& Grote, J. G. Comparison of magnetic properties of DNA-cetyltrimethyl ammonium complex with those of natural DNA. Sci. China Chem. 55, 814-821 (2012)

13 Tanaka, K. \& Okahata, Y. A DNA-lipid complex in organic media and formation of an aligned cast film. J. Am. Chem. Soc. 118, 10679-10683 (1996).

14 Ewert, K. K., Evans, H. M., Zidovska, A., Bouxsein, N. F., Ahmad, A. \& Safinya, C. R. A columnar phase of dendritic lipid-based cationic liposome-DNA complexes for gene delivery: hexagonally ordered cylindrical micelles embedded in a DNA honeycomb attice. J. Am. Chem. Soc. 128, 3998-4006 (2006).

15 Farago, O. \& Gronbech-Jensen, N. Simulation of self-assembly of cationic lipids and DNA into structured complexes. J. Am. Chem. Soc. 131, 2875-2881 (2009).

16 Kwon, Y. -W., Lee, C. H., Choi, D. H. \& Jin, J. -I. Materials science of DNA. J. Mater. Chem. 19, 1353-1380 (2009).

17 Su, W., Schuster, M., Bagshaw, C. R., Rant, U. \& Burley, G. A. Site-specific assembly of DNA-based photonic wires by using programmable polyamides. Angew. Chem. Int. Ed. 50, 2712-2715 (2011).

18 Steckl, A. J., Spaeth, H., You, H., Gomez, E. \& Grote, J. G. DNA as an optical material. Opt. Photonics News 22, 34-39 (2011).

19 Wang, L. L., Yoshida, J. \& Ogata, N. Self-assembled supramolecular films derived from marine deoxyribonucleic acid (DNA)-cationic surfactant complexes: large-scale preparation and optical and thermal properties. Chem. Mater 13, 1273-1281 (2001).

20 Endres, R. G., Cox, D. L. \& Singh, R. R. P. Colloquium: The quest for high-conductance DNA. Rev. Modern Phys 76, 195-214 (2004).

21 Wan, C., Fiebig, T., Kelley, S. O., Treadway, C. R., Barton, J. K. \& Zewail, A. H. Femtosecond dynamics of DNA-mediated electron transfer. Proc. Natl. Acad. Sci. USA 96, 6014-6019 (1999). 
22 Wang, Q. \& Fiebig, T. in Charge Migration in DNA: Perspectives from Physics, Chemistry, and Biology. (ed. Chakraborty, T.) 221-248 (Springer, Berlin, Germany, 2007).

23 Eley, D. D. \& Spivey, D. I. Semiconductivity of organic substances. 9. Nucleic acid in dry state. Trans. Faraday Soc 58, 411-417 (1962).

24 Grote, J. G., Hagen, J. A., Zetts, J. S., Nelson, R. L., Diggs, D. E., Stone, M. O., Yaney, P. P., Heckman, E., Zhang, C., Steier, W. H., Jen, A. K. Y., Dalton, L. R., Ogata, N., Curley, M. J., Clarson, S. J. \& Hopkins, F. K. Investigation of polymers and marinederived DNA in optoelectronics. J. Phys. Chem. B 108, 8584-8591 (2004).

25 Grote, J. G., Diggs, D. E., Nelson, R. L., Zetts, J. S., Hopkins, F. K., Ogata, N., Hagen, J. A., Heckman, E., Yaney, P. P., Stone, M. O. \& Dalton, L. R. DNA photonics [deoxyribonucleic acid]. Mol. Cryst. Liq. Cryst. 426, 3-17 (2005).

26 Ihmels, H. \& Otto, D. In Supermolecular Dye Chemistry 161-204 (2005).

27 LePecq, J. -B. \& Paoletti, C. A fluorescent complex between ethidium bromide and nucleic acids. Physical-chemical characterization. J. Mol. Biol. 27, 87-106 (1967).

28 Ohnishi, T. Properties of double-stranded DNA as a polyelectrolyte. Biophys. J 3, 459-468 (1963).

29 Record, Jr. M. T., Mazur, S. J., Melanfon, P., Roe, J. -H., Shaner, S. L. \& Unger, L. Double helical DNA: conformations, physical properties, and interations with ligands. Ann. Rev. Biochem. 50, 997-1024 (1981).

30 Muller, G. \& Fenyo, J. C. Effect of Polyion conformation on dye binding. 1 Fluorescence of Acridine-orange in presence of synthetic polyacids. J. Polym. Sci. Part A: Polym. Chem. 16, 77-87 (1978).

31 Klotz, I. M. \& Harris, J. U. Macromolecule-small molecule interactions - strong binding by intramolecularly cross-linked polylysine. Biochemistry 10, 923-926 (1971).

32 Olmsted, J. \& Kearns, D. R. Mechanism of ethidium-bromide fluorescence enhancement on binding to nucleic-acids. Biochemistry 16, 3647-3654 (1977).

33 Lee, J. E., Do, E. D., Lee, U. R., Cho, M. J., Kim, K. H., Jin, J. -I., Shin, D. H., Choi, S H. \& Choi, D. H. Effect of binding mode on the photoluminescence of CTMA-DNA doped with (E)-2-(2-(4-(diethylamino)styryl)-4H-pyran-4-ylidene)malononitrile. Polymer 49, 5417-5423 (2008).

34 Lee, U. R., Lee, J. E., Cho, M. J., Kim, K. H., Kwon, Y. -W. Jin, J. -I. \& Choi, D. H. Photoluminescence behaviors of organic soluble DNA bearing carbazole and pyrene derivatives as side-chain substituents and effect of the copolymer structure on the forster energy transfer process. J. Polym. Sci. Part A: Polym. Chem. 47, 5416-5425 (2009).

35 Liu, B., Gaylord, B. S., Wang, S. \& Bazan, G. C. Effect of chromophore-charge distance on the energy transfer properties of water-soluble conjugated oligomers. J. Am. Chem. Soc. 125, 6705-6714 (2003).

36 Kawahara, S., Uchimaru, T. \& Murata, S. Sequential multistep energy transfer: enhancement of efficiency of long-range fluorescence resonance energy transfer. Chem. Commun. 563-564 (1999).

37 Su, W., Bonnard, V. \& Burley, G. A. DNA-templated photonic arrays and assemblies: design principles and future opportunities. Chem. Eur. J 17, 7982-7991 (2011).

38 Yu, Y. J., Kwon, Y. -W., Kim, K. N., Do, E. D., Choi, D. H., Jin, J. -I., Shin, H. W., Kim, Y. R. Kang, I. J. \& Mikroyannidis, J. A. Highly fluorescing solid DNA-cationic polyelectrolyte complexes prepared from a natural DNA and a poly(fluorenevinylene-altphenylene) bearing quaternary ammonium pendants. Macromol. Res. 17, 245-249 (2009).

39 Furstenberg, A., Julliard, M. D., Deligeorgiev, T. G., Gadjev, N. I., Vasilev, A. A. \& Vauthey, E. Ultrafast excited-state dynamics of DNA fluorescent intercalators: new insight into the fluorescence enhancement mechanism. J. Am. Chem. Soc. 128, 7661-7669 (2006).

40 Kawabe, Y., Wang, L., Horinouchi, S. \& Ogata, N. Amplified spontaneous emission from fluorescent-dye-doped DNA-surfactant complex films. Adv. Mater. 12, 1281-1283 (2000).

$41 \mathrm{He}, \mathrm{G}$. S., Zheng, Q., Prasad, P. N., Grote, J. G. \& Hopkins, F. K. Infrared two-photonexcited visible lasing from a DNA-surfactant-chromophore complex. Opt. Lett. 31, 359-361 (2006)

42 Yu, Z., Li, W., Hagen, J. A., Zhou, Y., Klotzkin, D., Grote, J. G. \& Steckl, A. J. Photoluminescence and lasing from deoxyribonucleic acid (DNA) thin films doped with sulforhodamine. Appl. Opt. 46, 1507-1513 (2007)

43 Balan, N., Hari, M., Parameswaran, V. \& Nampoori, N. Selective mode excitation in dye-doped DNA polyvinyl alcohol thin film. Appl. Opt. 48, 3521-3525 (2009).

44 Leonetti, M., Sapienza, R., Ibisate, M., Conti, C. \& Lopez, C. Optical gain in DNA-DCM for lasing in photonic materials. Opt. Lett. 34, 3764-3766 (2009).

45 Mysliwiec, J., Sznitko, L., Sobolewska, A., Bartkiewicz, S. \& Miniewicz, A. Lasing effect in a hybrid dye-doped biopolymer and photochromic polymer system. Appl. Phys. Lett. 96, 141106 (2010).

46 Gurzadyan, G. G., Dmitriev, V. G. \& Nikogosyan, D. N. Handbook of Nonlinear Optical Crystals (Springer, Berlin; New York, 1999).

47 Williams, D. J. (ed. Nonlinear Optical Properties of Organic and Polymeric Materials (American Chemical Society, Washington, D.C., 1983).
48 Nalwa, H. S. \& Miyata, S. Nonlinear Optics of Organic Molecules and Polymers (CRC Press, Boca Raton, FL, 1997).

49 Sahraoui, B., Pranaitis, M., Gindre, D., Niziol, J. \& Kazukauskas, V. Opportunities of deoxyribonucleic acid complexes composites for nonlinear optical applications. J. Appl. Phys. 110, 083117 (2011).

50 Reintjes, J. F. Nonlinear Optical Parametric Processes in Liquids and Gases (Academic Press, New York 1984).

51 Kajzar, F., Messier, J. \& Rosilio, C. Nonlinear Optical-properties of thin-films of polysilane. J. Appl. Phys. 60, 3040-3044 (1986).

52 Lee, G. J., Cha, S. W., Jeon, S. J., Jin, J. -I. \& Yoon, J. S. Second-order nonlinear optical properties of unpoled bent molecules in powder and in vacuum-deposited film. J. Korean Phys. Soc. 39, 912-915 (2001).

53 Derkowska, B., Krupka, O., Smokal, V. \& Sahraoui, B. Optical properties of oxazalone derivatives with and without DNA-CTMA. Opt. Mater. 33, 1429-1433 (2011).

54 Nithyaja, B., Misha, H., Radhakrishnan, P. \& Nampoori, V. P. N. Effect of deoxyribonucleic acid on nonlinear optical properties of Rhodamine 6G-polyvinyl alcohol solution. J. Appl. Phys. 109, 023110 (2011)

55 Walter, S. R. \& Geiger, F. M. DNA on stage: showcasing oligonucleotides at surfaces and interfaces with second harmonic and vibrational sum frequency generation. J. Phys. Chem. Lett. 1, 9-15 (2010).

56 Hagen, J. A., Li, W., Steckl, J. \& Grote, J. G. Enhanced emission efficiency in organic light-emitting diodes using deoxyribonucleic acid complex as an electron blocking layer. Appl. Phys. Lett. 88, 171109 (2006).

57 Gomez, E. F., Spaeth, H. D., Steckl, J. \& Grote, A. J.G. Fabrication of natural DNAcontaining organic light emitting diodes. Proc. SPIE 8103, 81030A (2011).

58 Hirata, K., Oyamada, T., Imai, T., Sasabe, H., Adachi, C. \& Koyama, T. Electroluminescence as a probe for elucidating electrical conductivity in a deoxyribonucleic acid-cetyltrimethylammonium lipid complex layer. Appl. Phys. Lett. 85, 1627-1629 (2004).

59 Cho, M. J., Lee, U. R., Kim, Y. S., Shin, J., Kim, Y. M., Park, Y. W., Ju, B. K., Jin, J. I. \& Choi, D. H. Organic soluble deoxyribonucleic acid (DNA) bearing carbazole moieties and its blend with phosphorescent Ir(III) complexes. J. Polym. Sci. Part A: Polym. Chem. 48, 1913-1918 (2010).

60 Nakamura, K., Ishikawa, T., Nishioka, D., Ushikubo, T. \& Kobayashi, N. Color-tunable multilayer organic light emitting diode composed of DNA complex and tris(8hydroxyquinolinato)aluminum. Appl. Phys. Lett. 97, 193301 (2010).

61 Bandyopadhyay, A., Ray, A. K. \& Sharma, A. K. Use of DNA in the fabrication of solid state dye sensitized solar cells. J. Appl. Phys. 102, 064508 (2007).

62 O'Regan, B. \& Grätzel, M. A low-cost, high-efficiency solar cell based on dye-sensitized colloidal $\mathrm{TiO}_{2}$ films. Nature 353, 737-740 (1991).

63 Gullu, O., Cankaya, M., Baris, O. \& Turut, A. DNA-modified indium phosphide Schottky device. Appl. Phys. Lett. 92, 212106 (2008).

64 Kolachure, V. \& Jin, M. H. -C. in 33rd IEEE Photovoltaic Specialists Conference (IEEE, San Diego, CA, USA 2008).

65 Yengel, E., Wang, L., Ozkan, M. \& Ozkan, C. S. Effects of DNA and Pt-DNA electrodes on bulk heterojunction solar cells. Proc. SPIE 7411, 74110B (2009).

66 Kumar, C. V. \& Duff, M. R. DNA-based supramolecular artificial light harvesting complexes. J. Am. Chem. Soc. 131, 16024-16026 (2009).

67 Qi, H. J., Wang, L. X., Wong, K. W. \& Du, Z. L. DNA-quantum dot sensing platform with combined Forster resonance energy transfer and photovoltaic effect. Appl. Phys. Lett. 94, 143902 (2009).

68 Vaya, I., Gustavsson, T., Miannay, F. A., Douki, T. \& Markovitsi, D. Fluorescence of natural DNA: from the femtosecond to the nanosecond time scales. J. Am. Chem. Soc. $132,11834-11835$ (2010).

69 Markovitsi, D., Gustavsson, T. \& Vaya, I. Fluorescence of DNA duplexes: from model helices to natural DNA. J. Phys. Chem. Lett. 1, 3271-3276 (2010).

70 Hannestad, J. K., Sandin, P. \& Albinsson, B. Self-assembled DNA photonic wire for long-range energy transfer. J. Am. Chem. Soc. 130, 15889-15895 (2008).

71 Ner, Y., Grote, J. G., Stuart, J. A. \& Sotzing, G. A. White luminescence from multipledye-doped electrospun DNA Nanofibers by fluorescence resonance energy transfer. Angew. Chem. Int. Ed. 48, 5134-5138 (2009).

72 Ozhalici-Unal, H. \& Armitage, B. A. Fluorescent DNA nanotags based on a selfassembled DNA tetrahedron. ACS. Nano. 3, 425-433 (2009).

73 Benvin, A. L., Creeger, Y., Fisher, G. W., Ballou, B., Waggoner, A. S. \& Armitage, B. A. Fluorescent DNA nanotags: supramolecular fluorescent labels based on intercalating dye arrays assembled on nanostructured DNA templates. J. Am. Chem. Soc. 129, 2025-2034 (2007).

74 Jin, J. -I. \& Grote, J. G. (eds.) Materials Science of DNA (CRC Press, Boca Raton, FL, 2012). 

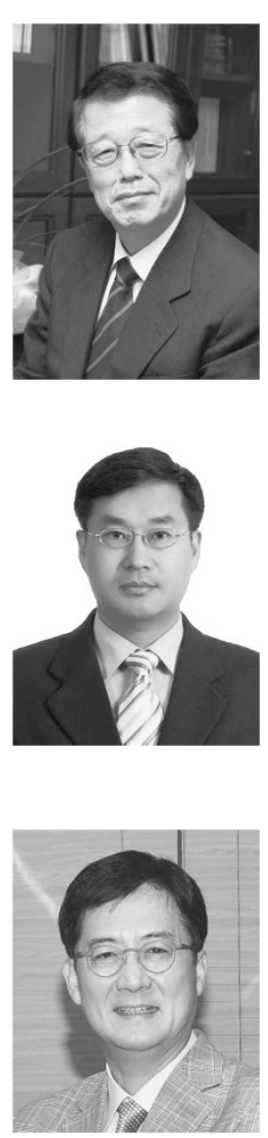

Professor Jung-Il Jin, born in Seoul, Korea in 1942, received his BS(1964) and MS(1966) degrees from the Seoul National University and the Ph D degree from the City University of New York in 1969. After working for the Stauffer Chemical Co. USA for 5 years, he joined the Chemistry Department of the Korea University, Seoul in 1974. He is now the Professor Emeritus of the same university. He was the president of the Korean Polymer Society(1997), the Korean Chemical Society(2000), and IUPAC(2008-2009). He is presently the president of the Korean Federation of Science Culture and Education Societies and the Korean Council of Science Editors. He is the honorary professor of the Jilin University and the Beijing University of Chemical Technology in China. He received numerous awards including Korean Science Award, International Award of SPSJ, and the Seoul City Award. He has published more than 400 papers on liquid crystalline polymers, polyconjugated polymers and materials science of DNA.

Dr Young-Wan Kwon was born in Shinan, Korea in 1967. He received his BS and MS, degrees in 1993 and 1996 from Korea University. He joined LG Electronics (Korea) in 1996 and worked as a researcher in LCD laboratory. He was engaged in the R\&D of new LCD mode, diffusing films, and printing of color filter of LCD displays from 1996 to 2002. He received his PhD degree from Korea University (2006) under the supervision of Professor Jung-Il Jin. Since 2002 he has been mainly engaged in the research of materials science of DNAs such as electrical, electrooptical, optical and magnetic properties of natural and modified DNAs. Now, he is focusing his research on magnetism of natural and modified DNAs, discotic liquid crystals and polymeric materials. He is now a Research Professor of the Institute of Basic Science of the Korea University.

Dr Dong Hoon Choi was born in Seoul, Korea in 1960. He received his BS and MS, degrees in 1984 and 1986 from Seoul National University. He received his Doctoral degree of Engineering from University of Michigan-Ann Arbor (1991). In 1992, he moved to Korea Institute of Science and Technology located in Seoul, Korea and worked as a senior scientist in Functional Polymer Chemistry Laboratory. In 1995-2005, he taught as a professor in Kyung Hee University. In the spring of 2005, he moved to Korea University, Seoul, Korea and became a professor in the Department of Chemistry. He is now the director of Priority Research Center (PRC) supported by MEST in Korea. His group was nominated to be a National Leading Research Laboratory (NLRL) supported by the National Research Foundation of Korea in 2012. He has published 260 SCI papers and owns 35 patents. 